\title{
Investigating the observed sensitivities of air-quality extremes to meteorological drivers via quantile regression
}

\author{
W. C. Porter ${ }^{1}$, C. L. Heald ${ }^{1}$, D. Cooley ${ }^{2}$, and B. Russell ${ }^{2}$ \\ ${ }^{1}$ Massachusetts Institute of Technology, Cambridge, Massachusetts, USA \\ ${ }^{2}$ Colorado State University, Fort Collins, Colorado, USA \\ Correspondence to: W. C. Porter (wporter@mit.edu)
}

Received: 23 March 2015 - Published in Atmos. Chem. Phys. Discuss.: 19 May 2015

Revised: 13 August 2015 - Accepted: 19 August 2015 - Published: 21 September 2015

\begin{abstract}
Air pollution variability is strongly dependent on meteorology. However, quantifying the impacts of changes in regional climatology on pollution extremes can be difficult due to the many non-linear and competing meteorological influences on the production, transport, and removal of pollutant species. Furthermore, observed pollutant levels at many sites show sensitivities at the extremes that differ from those of the overall mean, indicating relationships that would be poorly characterized by simple linear regressions. To address this challenge, we apply quantile regression to observed daily ozone $\left(\mathrm{O}_{3}\right)$ and fine particulate matter $\left(\mathrm{PM}_{2.5}\right)$ levels and reanalysis meteorological fields in the USA over the past decade to specifically identify the meteorological sensitivities of higher pollutant levels. From an initial set of over 1700 possible meteorological indicators (including 28 meteorological variables with 63 different temporal options), we generate reduced sets of $\mathrm{O}_{3}$ and $\mathrm{PM}_{2.5}$ indicators for both summer and winter months, analyzing pollutant sensitivities to each for response quantiles ranging from 2 to $98 \%$. Primary covariates connected to high-quantile $\mathrm{O}_{3}$ levels include temperature and relative humidity in the summer, while winter $\mathrm{O}_{3}$ levels are most commonly associated with incoming radiation flux. Covariates associated with summer $\mathrm{PM}_{2.5}$ include temperature, wind speed, and tropospheric stability at many locations, while stability, humidity, and planetary boundary layer height are the key covariates most frequently associated with winter $\mathrm{PM}_{2.5}$. We find key differences in covariate sensitivities across regions and quantiles. For example, we find nationally averaged sensitivities of 95th percentile summer $\mathrm{O}_{3}$ to changes in maximum daily temperature of approximately $0.9 \mathrm{ppb}^{\circ} \mathrm{C}^{-1}$, while the sensitivity of 50th percentile summer $\mathrm{O}_{3}$ (the annual median) is only $0.6 \mathrm{ppb}^{\circ} \mathrm{C}^{-1}$. This
\end{abstract}

gap points to differing sensitivities within various percentiles of the pollutant distribution, highlighting the need for statistical tools capable of identifying meteorological impacts across the entire response spectrum.

\section{Introduction}

Poor air quality is projected to become the most important environmental cause of premature human mortality by 2030 (WHO, 2014). Long-term exposure to high levels of ozone $\left(\mathrm{O}_{3}\right)$ has been linked to increased risk of respiratory illness, while chronic exposure to elevated fine particulate matter $\left(\mathrm{PM}_{2.5}\right)$ is associated with lung cancer, respiratory disease, and cardiovascular disease (e.g., Dockery et al., 1993; Jerrett et al., 2009; Krewski et al., 2009; Pope III et al., 2009). In addition to these consistently documented risks of chronic exposure, there is some evidence that acute exposures to pollution may themselves carry risks to human health above and beyond those of the long-term mean exposures (Bell et al., 2005). Thus, high pollution events may be responsible for a larger fraction of annual acute mortality. In addition, particularly extreme events may hinder day-to-day activities, and require the implementation of drastic tactical air pollution control measures (e.g., the temporary banning of vehicles with even-numbered license plates from driving in Paris during the spring of 2015). Despite the lack of an observed threshold concentration for detrimental impacts of air pollution (e.g., Dockery et al., 1993), ambient air-quality regulations are typically implemented as thresholds, with penalties for exceedances. For example, in the USA, pollution standards for $\mathrm{O}_{3}$ and $\mathrm{PM}_{2.5}$ include limits on not only mean 
annual values (in the case of $\mathrm{PM}_{2.5}$ ) but also on thresholds for high annual values (equivalent to the averaged 98th or 99th percentiles for $\mathrm{PM}_{2.5}$ and $\mathrm{O}_{3}$, respectively). Thus, predicting and understanding potential changes in extreme air pollution episodes is central to both air pollution policy and human health concerns.

A changing climate may modulate air quality, with implications for human health. Pollutant formation, transport, lifetime, and even emissions all depend, to a certain degree, on local meteorological factors (Jacob and Winner, 2009; Tai et al., 2010), meaning that changes in the behaviors of these factors will often lead to changes in pollutant levels and exposure risks. Understanding the relationships between meteorological variability and observed pollutant levels will be critical to the development of robust pollution projections, as well as sound pollution control strategies. However, while straightforward sensitivity analyses using long-term averages and simple linear regressions provide valuable information on mean pollutant behavior, they are insufficient for analyses of extreme behaviors. Drivers and sensitivities characteristic of average pollutant responses will not necessarily be reflected throughout the entire pollutant distribution. To evaluate these relationships statistically, alternative methodologies must be used.

Previous studies examining the impact of meteorology on pollution levels have addressed the problem using a variety of tools. Modeling sensitivity studies offer a direct means of comparing the impacts of large-scale scenarios or individually adjusted parameters, allowing for a degree of comparison and replication that is impossible using only observations (e.g., Hogrefe et al., 2004; Mickley et al., 2004; Murazaki and Hess, 2006; Steiner et al., 2006; Heald et al., 2008). From such output, pollutant levels under multiple conditions or scenarios can be evaluated more or less in the same way that observed levels are, including the examination of global burdens, regional patterns, or even local exceedance frequencies as a function of meteorological changes. However, while these tools are powerful, it can be difficult to verify and understand projected changes due to the high degree of complexity of these models. On the other hand, observationbased examinations (e.g., Bloomer et al., 2009; Rasmussen et al., 2012) are tied closely to the actual underlying physical processes producing changes in pollutant levels, but are naturally limited in terms of identifying and quantifying the impacts of individual drivers - it is difficult to separate the impacts of different meteorological factors without the benefit of multiple sensitivity comparisons afforded by models.

Ordinary least-squares (OLS) regressions are effective tools for identifying trends and sensitivities in the distribution of pollution levels as a whole, especially for wellbehaved data showing uniform sensitivities. Previous studies have analyzed the impacts of changes in weather and climate on $\mathrm{O}_{3}$ and $\mathrm{PM}_{2.5}$ levels (e.g., Brasseur et al., 2006; Liao et al., 2006), finding connections between specific meteorological conditions and mean pollutant response. In particular, the

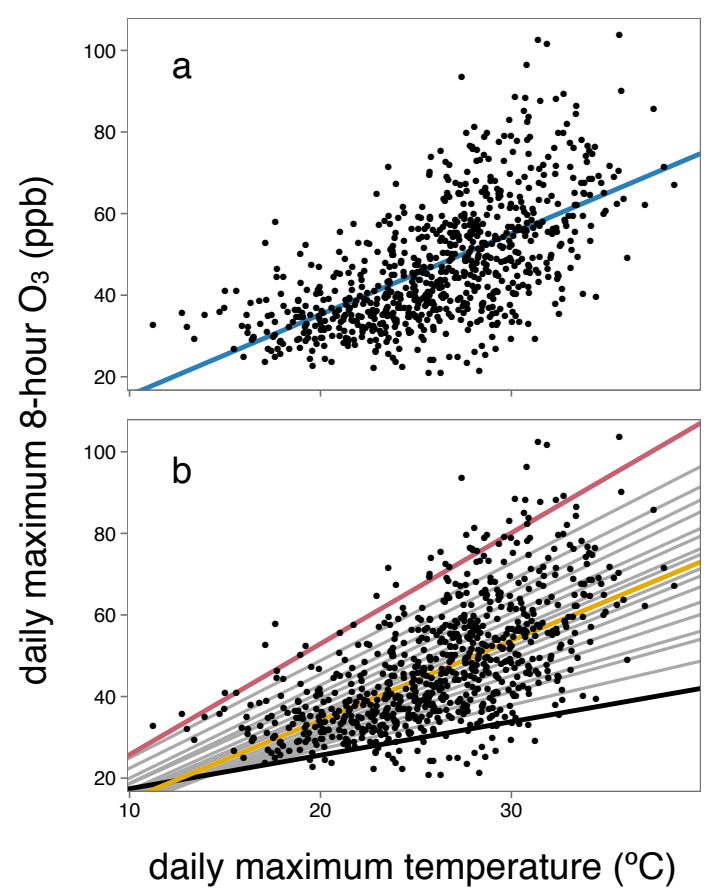

Figure 1. Daily maximum $8 \mathrm{~h} \mathrm{O}_{3}$ vs. maximum daily temperature for an example site in Essex County, MA (JJA, 2004-2012). An ordinary least-squares regression line (a) captures the general trend, but is unable to represent the increase of variability in the distribution with increasing temperature. Using individual quantile regressions ranging from 5 th to 95 th percentiles (b), the increased sensitivity of higher quantiles to increased temperatures becomes apparent.

sensitivity of surface $\mathrm{O}_{3}$ levels to changes in climate - the socalled "climate change penalty" (Wu et al., 2008) - has been examined in multiple studies worldwide (e.g., Bloomer et al., 2009), but previous examinations of individual meteorological sensitivities have typically produced single, monovariate estimates for changes in $\mathrm{O}_{3}$ given changes in each driver (e.g., temperature). However, when the variability of a given response is itself a function of the independent variable, as in Fig. 1a, the information provided by such regressions is less valuable for describing the specific response across the distribution - especially at the extremes (defined here as pollutant levels below the 5 th quantile or above the 95 th quantile). If the sensitivities of high $\mathrm{O}_{3}$ extremes to temperature tend to be higher than those of median to low $\mathrm{O}_{3}$ days (as is the case at many polluted locations), a single sensitivity value would underestimate the increase in high $\mathrm{O}_{3}$ event frequencies and magnitudes, given rising temperatures.

This situation is one common example of a distribution that might be better characterized through the use of more advanced statistical tools, such as quantile regression (QR) (Koenker and Bassett Jr., 1978). A semi-parametric estimator, quantile regression seeks to minimize the sum of a linear (rather than quadratic) cost function, making it less sensi- 
tive to outliers than OLS regression. Unweighted, this simple change produces a conditional median (or 50th quantile regression), rather than the conditional mean of OLS regression. Applying appropriately chosen weights to the positive and negative residuals of this cost function then targets specific percentiles of the response, allowing for the quantification of sensitivity across nearly the entire response distribution. An example of this regression performed across a broad range of percentiles is shown in Fig. 1b, including the 5th quantile in black, the 50th quantile in yellow, and the 95th quantile in red.

Here, we apply multivariate QR to an analysis of meteorological drivers of $\mathrm{O}_{3}$ and $\mathrm{PM}_{2.5}$, with the goal of identifying the covariates most correlated with changes in peak pollutant levels throughout the USA, and how these differ from the median response. Such a statistical examination of historical observations can provide a valuable reference point for the evaluation of model-predicted extremes, as well as a platform for short-term pollutant projections.

\section{Methodology}

\subsection{Inputs}

We use $\mathrm{O}_{3}$ and $\mathrm{PM}_{2.5}$ measurements from the US Environmental Protection Agency's (EPA) Air Quality System (AQS) network, including daily peak $8 \mathrm{~h}$ average measurements of $\mathrm{O}_{3}$ and daily mean $\mathrm{PM}_{2.5}$ levels. All stations with at least 150 valid maximum daily $8 \mathrm{~h}$ averages between 2004 and 2012 are included in this study, totaling 1347 stations for summer $\mathrm{O}_{3}, 675$ stations for winter $\mathrm{O}_{3}, 647$ stations for summer $\mathrm{PM}_{2.5}$, and 636 stations for winter $\mathrm{PM}_{2.5}$ (locations and 95th percentile concentrations shown in Fig. 2).

Meteorological variables are taken from the National Centers for Environmental Prediction (NCEP) North American Regional Reanalysis (NARR) product (Mesinger et al., 2006). With a spatial resolution of $32 \mathrm{~km}$ and 8 output fields per day (representing 3-hourly averages), NARR output provides a reasonable spatial and temporal match for each of the AQS stations of interest. While the NARR product represents modeled output and includes its own errors and biases when compared to observations, it allows for the consistent use of many variables at high spatial and temporal resolution, most of which would not be available at all included AQS stations examined here. NARR reanalyses have been used in previous examinations of meteorological air pollution drivers with some success (e.g., Tai et al., 2010).

\subsection{Meteorological variable generation}

As an initial step towards understanding the impacts of meteorology on pollutant extremes, we construct a large set of possible meteorological covariates, including NARR meteorological variables for a range of time frames. By extending the initial scope of possible drivers, we attempt to capture
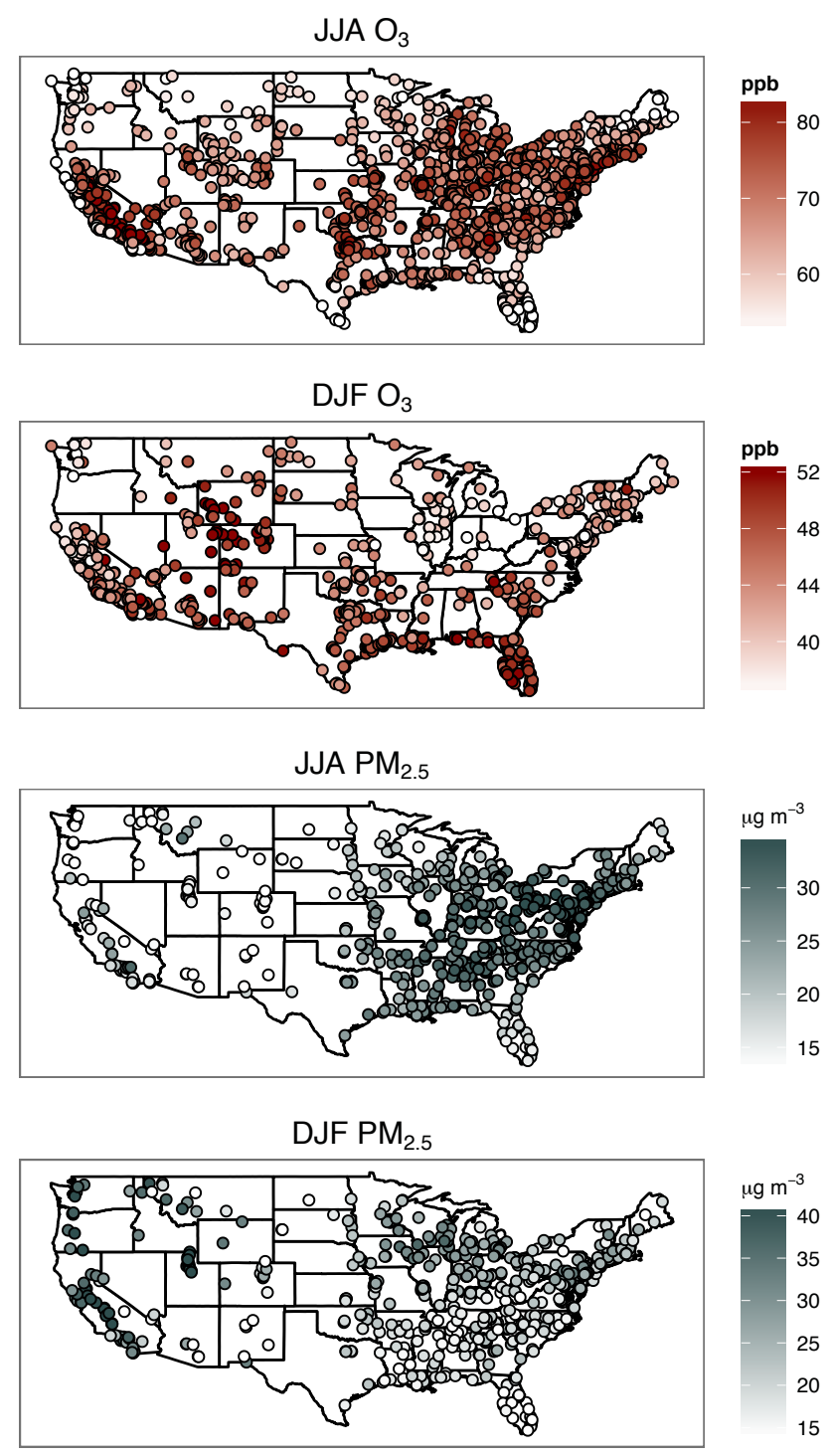

Figure 2. Location of AQS stations included in this study. The magnitude of each station's 95th percentile measurement is indicated by color.

the important factors and interactions, including not only effects that were important at all sites, but also those that stood out only in particular regions or types of locations. To this end, we begin by considering as many potential indicators as possible, gradually trimming the list down to a final set to be used in the multivariate quantile regressions. We use the 3-hourly NARR output to reconstruct hourly resolution diurnal cycles for each meteorological variable at each station through time series cubic splines and bilinear interpolation of the gridded fields to station latitudes and longitudes. In some cases regional means were included, primarily due to insufficient variability in individual cell values for that variable at some sites. 
In addition to the raw variables available through NARR output, we calculate several derived parameters. The synoptic recirculation of air has been linked to elevated pollutant concentrations at many sites around the world, especially in coastal regions where diurnal wind patterns are prone to recirculation (Alper-Siman Tov et al., 1997; St. John and Chameides, 1997; Yimin and Lyons, 2003; Zhao et al., 2009). When air masses are returned to a site with ongoing emissions, the buildup of precursor concentrations may generate exceptionally high pollutant levels. To measure this effect we calculate a daily recirculation potential index (RPI) from surface wind speeds based on the ratio between the vector sum magnitude $(L)$ and scalar sum $(S)$ of wind speeds over the previous $24 \mathrm{~h}$ (Levy et al., 2009):

$\mathrm{RPI}=1-\left(\frac{L}{S}\right)$.

A high RPI (close to 1) indicates that, regardless of individual hourly wind-speed magnitudes, the total displacement of air over the previous 24 hours was low, potentially leading to a pollutant buildup. Meanwhile, a very low RPI (close to 0) indicates steady, consistent wind, advecting air masses away from a location.

Stagnation, or the relative stability of tropospheric air masses, is another meteorological phenomenon previously cited as a driver of pollutant extremes (Banta et al., 1998; Jacob and Winner, 2009; Valente et al., 1998). While some of the raw meteorological fields (e.g., wind speed and precipitation) are already themselves good indicators of local stagnation, lower-tropospheric stability (LTS), the difference between surface and $700 \mathrm{hPa}$ potential temperatures, is also calculated as a reflection of temperature inversion strength in the lower troposphere (Klein and Hartmann, 1993). Temperature inversions, in which the daytime pattern of air being warmer near the Earth's surface is reversed, generally lead to stable, stagnant conditions well-suited for the buildup of pollutants such as $\mathrm{O}_{3}$ and $\mathrm{PM}_{2.5}$. This phenomenon can be particularly pronounced in areas with geographical barriers to horizontal transport, such as the basins of Los Angeles and Salt Lake City (Langford et al., 2010; Pope 3rd, 1991).

From the selected set of raw and derived NARR meteorological fields (Table 1), we generate a range of temporal variables for each individual meteorological variable, including extrema and means for each $24 \mathrm{~h}$ day, as well as for $8 \mathrm{~h}$ daytime and previous $8 \mathrm{~h}$ nighttime ranges. To include possible long-term impacts of these meteorological variables, each of the 9 daily values are then extended into 3- and 6-day maxima, minima, and means, as well as a 1-day delta variable to show $24 \mathrm{~h}$ change, resulting in 63 total temporal options for each listed meteorological variable.

\subsection{Fire proximity metric}

Biomass burning emissions can impact pollutant concentrations (e.g., Streets et al., 2003) with indirect correlations to daily meteorological variability, making it a potentially confounding factor when performing analyses using meteorological variables alone. To help examine and quantify the likely impact of fires on observed pollutant levels, we create a simple fire metric to represent the spatial and temporal proximity of each site to satellite-observed burn locations. Using output from the Moderate Resolution Imaging Spectroradiometer (MODIS) Global Monthly Fire Location Product (Giglio et al., 2003; Justice et al., 2002), we estimate the total fire proximity impact for each site by applying spatial and temporal decays to burn detection confidence values, and summing these values across all detected pixels through the equation

$$
F=\log \left(\sum_{i} \frac{1}{r} \frac{1}{2^{t}} \operatorname{conf}\right) .
$$

Here, the fire proximity index $F$ is a function of the distance $(r)$ and number of elapsed days $(t$; ranging from 0 to 6) separating a station from a MODIS-detected burn pixel with a given confidence value (conf), summed over all nearby burn pixels $(i)$. The resulting proximity metric does not take transport, precipitation, or any other meteorological variables into account, simply producing higher values for stations near burning (or recently burned) locations. A comprehensive treatment of biomass burning emissions and transport requires accurate information on many complex factors, including fuel type, burn intensity, and smoke injection heights (Val Martin et al., 2010; Wiedinmyer et al., 2011), and fully representing these factors to generate a robust estimate for the influence of fire emissions goes well beyond the scope of this work. However, considering both the stochastic nature of large fire events and the importance of biomass burning on air-quality variability, we use this cumulative proximity metric as an intermediate measure.

\subsection{Meteorological variable selection}

Combining the 63 described temporal options with all chosen raw and derived meteorological variables results in over 1700 possible pollutant indicators, making variable selection problematic. With driver identification an important goal of this work, we initially keep the selection procedure as open as possible, maximizing the first sweep of candidates and only eliminating possible drivers after thorough evaluation (Fig. 3). However, indiscriminate inclusion of additional variables opens the strong likelihood of problems related to overfitting and multicollinearity. Furthermore, for the sake of comparison between stations, we aim for a single set of indicator variables for the entire set of observation sites included, making selection on a station-by-station basis impractical. For these reasons we utilize a stepwise multivariate approach based on combining covariate rankings at individual stations into a single selection metric. To reduce the computational cost of variable selection initially we use a testing subset of stations, including 10 stations (with varying degrees of mean 
Table 1. Meteorological fields used in variable selection procedure. Each NARR field shown was included using nine different possible daily values ( $24 \mathrm{~h} \mathrm{max} / \mathrm{min} / \mathrm{mean}, 8 \mathrm{~h}$ daytime max/min/mean, previous $8 \mathrm{~h}$ nighttime max/min/mean), as well as longer term (3- and 6-day) aggregates and 1-day deltas of those daily values. Variables marked "9x9" represent regional means, and were generated by averaging the $9 \times 9$ square of NARR grid cells centered around each station location (roughly $290 \mathrm{~km}$ per side).

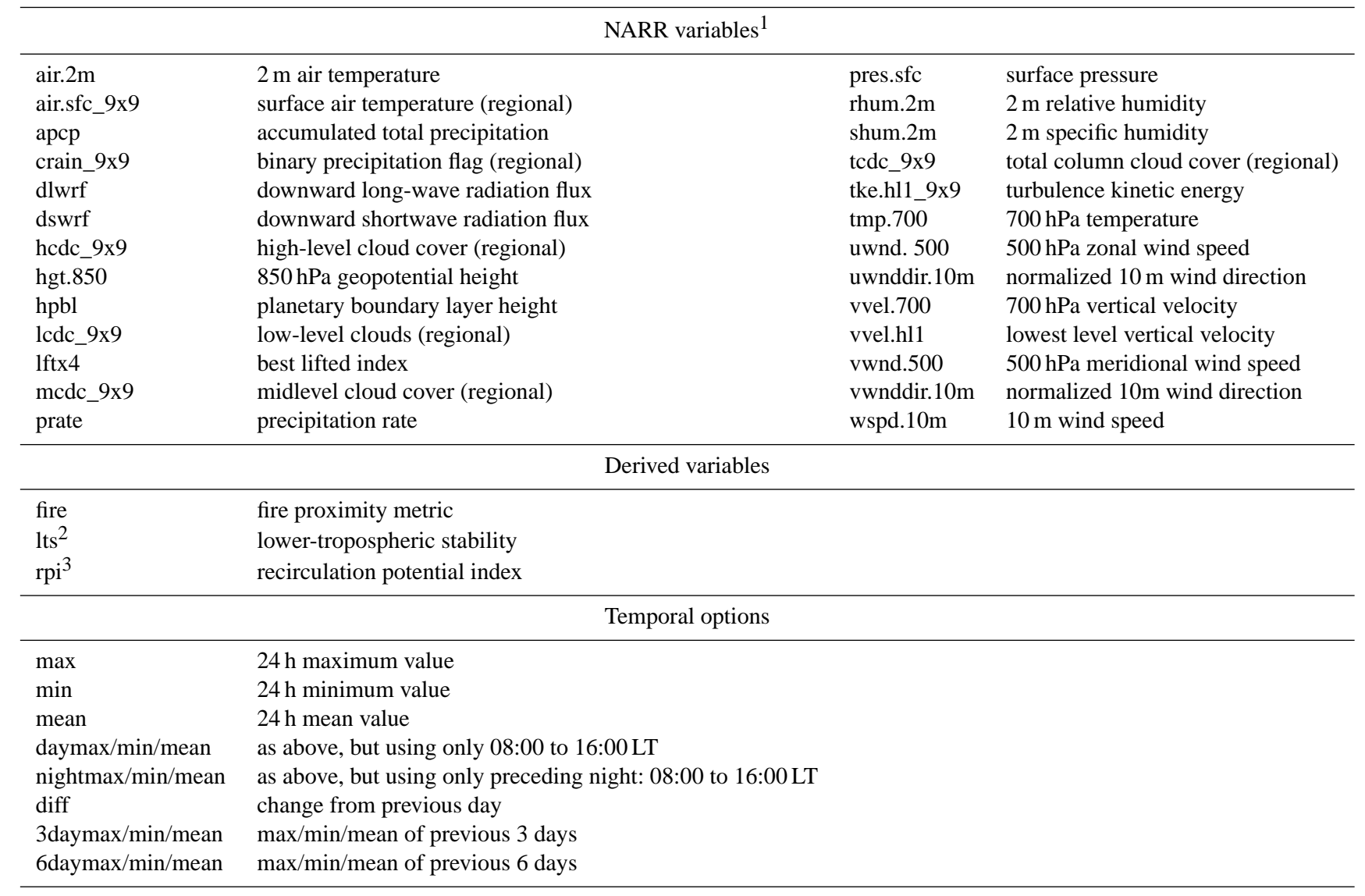

${ }^{1}$ Mesinger et al. (2006), ${ }^{2}$ Klein and Hartmann (1993), and ${ }^{3}$ Levy et al. (2009).

pollutant levels) from each of the 10 EPA regions (shown in Figs. 4, 5, 7, and 8). We then use observed pollutant levels (maximum $8 \mathrm{~h}$ average $\mathrm{O}_{3}$ and daily average $\mathrm{PM}_{2.5}$ ) from each of these 100 stations to evaluate and select key indicators from the full set of possible meteorological variables included. Meteorological variable selection is performed independently for ozone and $\mathrm{PM}_{2.5}$, as well as for summer and winter seasons.

We select meteorological indicators using 90th percentile quantile regressions evaluated with the Bayesian information criterion (BIC) metric, a statistical tool closely related to the Akaike information criterion (AIC) and similarly based on the likelihood function (Schwarz, 1978; Lee et al., 2014). BIC evaluates the likelihood of a given set of indicators representing the best set possible, given a set of associated responses (in this case, daily pollutant levels), with lower BIC values indicating a stronger statistical model (i.e., the set of predictive meteorological indicators being evaluated). To perform stepwise variable selection, we quantify the benefit (via BIC) of adding each individual variable candidate to

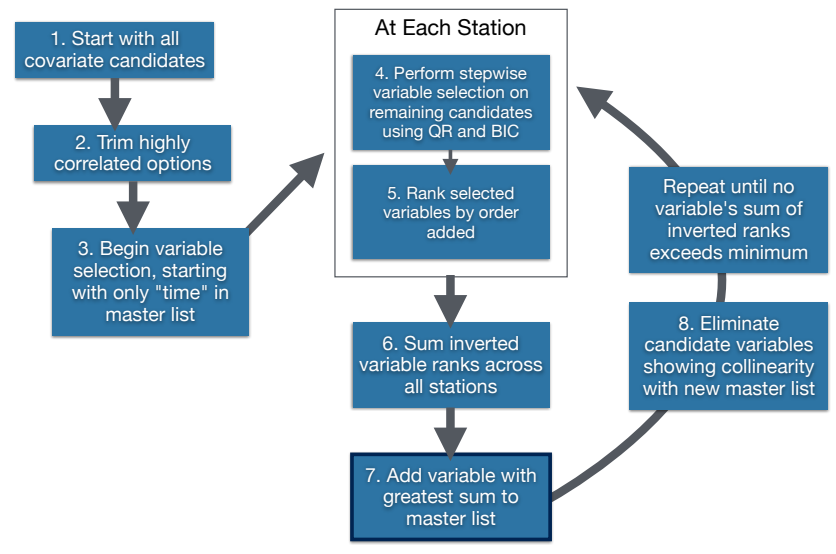

Figure 3. Flowchart of variable selection procedure described in Sect. 2.4. 
the list of selected variables in turn. Large reductions in BIC indicate a more-important variable, while small reductions $(\Delta \mathrm{BIC}<2)$ indicate a less-important variable. Unlike other goodness of fit metrics such as the coefficient of determination $R^{2}$, BIC values say nothing about the overall strength of the predictive model as a whole, but rather serve to compare the relative effectiveness of multiple statistical models attempting to explain the same set of results. However, again unlike $R^{2}$, both BIC and (to a lesser extent) AIC penalize the inclusion of extraneous indicators, reducing the chance of overfitting. While there is some discussion within the statistical literature regarding the strengths of BIC vs. AIC, both are considered versatile, robust tools in the evaluation of statistical models (Burnham and Anderson, 2004; Yang, 2005), and applicable to quantile regression if errors are assumed to follow an asymmetric Laplace distribution (Geraci and Bottai, 2007). Note that while the 90th percentile of pollution levels is lower than the 95th quantile targeted later in this study, the slightly reduced value is chosen to improve robustness during the initial variable selection phase.

We begin variable selection by using only time (measured in days elapsed) as a predictor variable, accounting for any linear trend in pollutant behavior over the course of the observed period (Fig. 3, step 3). From there, we identify the most impactful temporal option (daily maximum, mean, minimum, etc.) available for a single meteorological variable (e.g., surface temperature). We perform stepwise variable selection at each station independently, selecting the candidate temporal option producing the greatest reduction in BIC (and therefore greatest improvement in the statistical model), and continuing until no further improvement is possible (step 4). We then rank the final set of chosen variables at each station by order of selection (step 5), invert those ranks, and sum these inverted ranks over all 100 test stations (step 6). This sum represents an overall importance metric, and will be large for variables that either appear somewhat valuable at many stations, or that appear to be exceptionally valuable at just a few stations. We then add the single temporal option with the greatest summed total to the master list of selected variables. With a new indicator chosen we filter the remaining candidates (step 8), eliminating poor performers (those selected at too few sites in the previous round) or those exhibiting collinearity with the current master list $\left(R^{2} \geq 0.6\right.$ relative to previously selected covariates). After this pruning process we start the selection routine again for all remaining candidates, using time and all previously selected variables as fixed covariates in the evaluation process. We repeat this cycle until no temporal candidates exhibiting summed ranks higher than our chosen threshold remain for the current meteorological variable, after which the temporal variable selection starts anew with the next meteorological parameter. Once temporal variable options have been filtered down for each individual meteorological covariate through this selection process, we gather all selected variables together and repeat the same procedure using the combined set of approx- imately 300 candidates, finally arriving at trimmed a down set of less than 20 meteorological indicators for each pollutant species and season (Table 2, top). The selection process is somewhat sensitive to the percentile used for the regression, as evidenced by the different variables selected using the 50th percentile rather than the 90th (Table 2, below). While most high-ranked meteorological variables show up using both selection processes, there are noticeable differences, especially in the temporal options chosen.

Through this routine, variables can stand out for selection by being either moderately important at many sites, or by being very important at fewer sites. By adjusting the threshold parameter for variable selection, the scope of variable inclusion can be tuned to a certain extent. Higher thresholds end the selection process sooner, as fewer and fewer new variables are ranked highly at enough stations to meet the summed value requirements, while lower values allow the process to continue adding less important variables. In this work we identify and compare both a concise "core" set of indicators (variables with summed inverse ranks of at least 2) and a "full" set of indicators (variables with summed inverse ranks of at least 1).

It should be noted that the NARR fields used to provide our input meteorological covariates likely exhibit intrinsic errors and biases which will certainly affect the predictive power of our models, as well as the strength of our variable selection process itself. Variables which are better represented (e.g., temperature) will have an advantage compared to other potentially important variables with greater uncertainties, such as precipitation.

\subsection{Quantile regression}

The final sets of indicator variables represent those covariates most broadly associated with changes in high pollutant levels due to meteorological factors at the 100 chosen test sites. Using these selected meteorological variables, we next perform linear multivariate quantile regression to identify sensitivities for percentiles from 2 to $98 \%$ at each station in the full set of AQS sites. From these regressions we collect summer (JJA) and winter (DJF) quantile sensitivities of $\mathrm{O}_{3}$ and $\mathrm{PM}_{2.5}$ to each meteorological variable for each AQS station.

\section{Results}

To assess relative covariate importance across the USA we normalize quantile sensitivities to standard deviations of pollutant and indicator fluctuations and rank them in relation to each other at each site. Top-ranking covariates for any given station, then, are those whose variabilities (in normalized units of standard deviations) are most responsible for variability in the observed pollutant. Figures 4, 5, 7, and 8 show each variable's frequency of appearing as the first or second most important indicator by this metric, with simi- 


\section{Top Covariates: Summer $\mathrm{O}_{3}$}

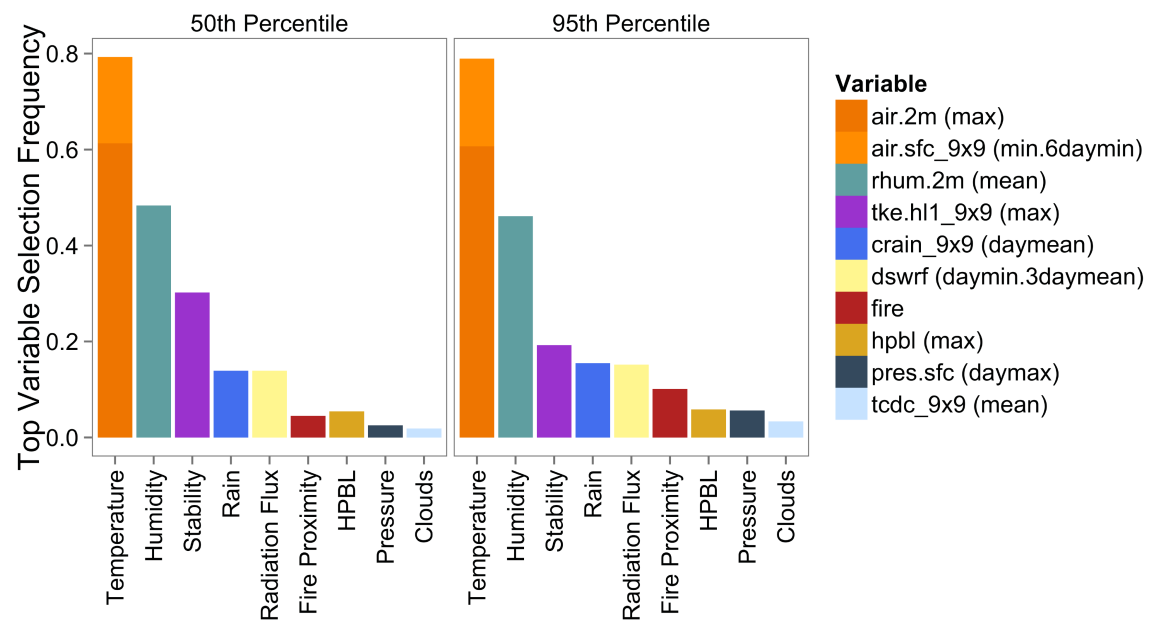

Normalized 95th Quantile Regression Coefficients for Most Frequent by Region

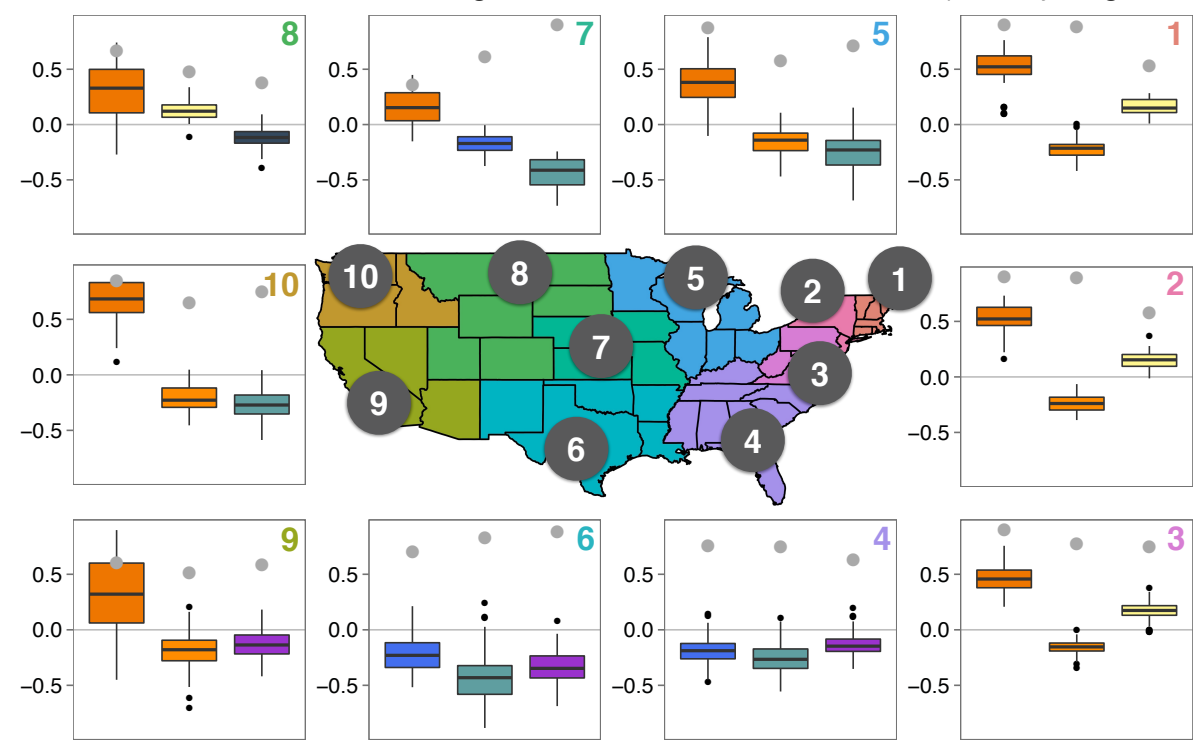

Figure 4. Frequency at which normalized 95th percentile QR coefficients for selected variables were in the top two out of all included variables (above) for summer $\mathrm{O}_{3}$, and box plots of normalized regression coefficients for top three covariates in each region (below). Specific meteorological variables (shown in legend) have been grouped into categories shown on the $x$ axis of the bar plot. Colors on inset box plots correspond to legend in above panel, and gray dots indicate the fraction of stations showing a statistically significant relationship ( $p \leq 0.05$ ) to the indicated covariate in that region. EPA Region numbers are inset on top-right of box plot panels.

lar variables grouped together into columns. We compare the covariates most associated with the 95th and 50th percentile of pollutant concentrations, finding similar, though not identical, frequencies between top performers for the two quantiles.

\subsection{Summer $\mathrm{O}_{3}$}

In the summertime, covariates linked to high-percentile $\mathrm{O}_{3}$ are dominated by a positive correlation with temperature at most sites (Fig. 4, top panel), consistent with previous mod- eling sensitivity conclusions (Jacob and Winner, 2009). Altogether, $49 \%$ of the analyzed sites show maximum daily surface air temperature as the meteorological variable with the greatest normalized slope relative to observed maximum $8 \mathrm{~h}$ average $\mathrm{O}_{3}$ concentrations, and it is within the top five most influential variables at $79 \%$ of all sites. Underlying reasons for the dominance of temperature as a driver of observed $\mathrm{O}_{3}$ include a positive correlation with biogenic emissions of isoprene (a potential precursor of $\mathrm{O}_{3}$ ), a negative correlation with the lifetime of peroxyacetyl nitrate (PAN; an important reservoir species for $\mathrm{NO}_{\mathrm{x}}$ and $\mathrm{HO}_{\mathrm{x}}$ radicals), and an asso- 


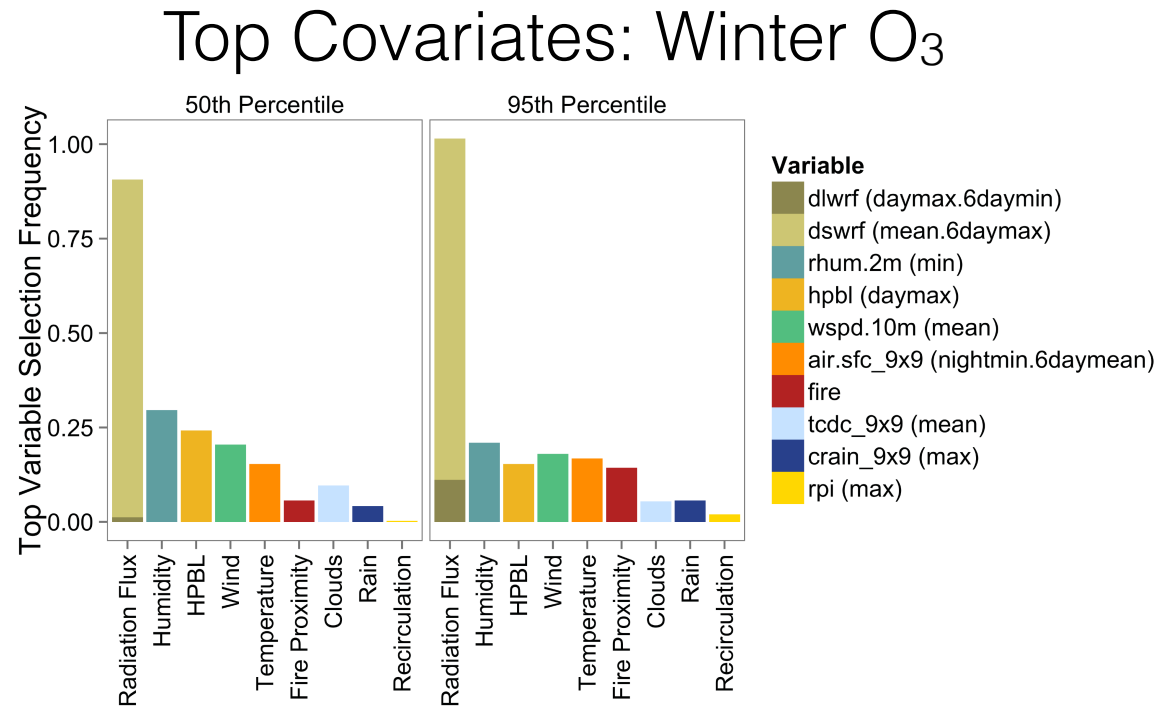

Normalized 95th Quantile Regression Coefficients for Most Frequent by Region

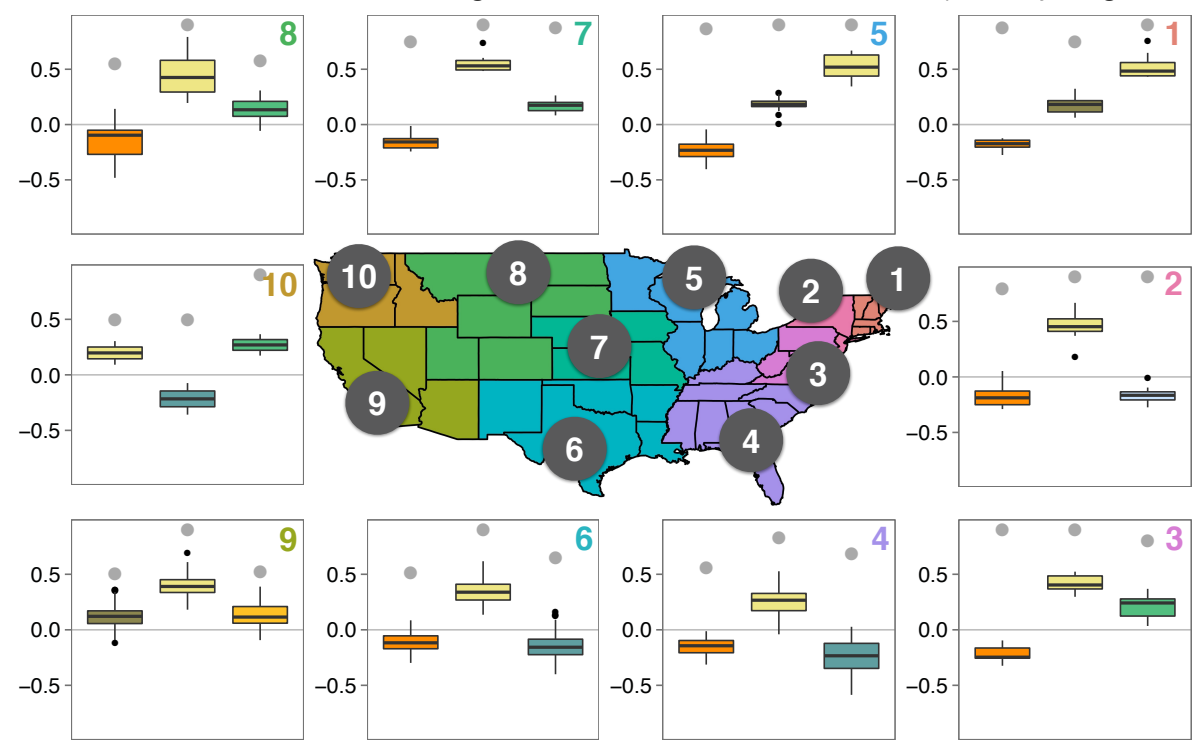

Figure 5. Same as Fig. 4, but for winter $\mathrm{O}_{3}$.

ciated correlation between higher temperatures and bright, stagnant conditions (Jacob and Winner, 2009).

While maximum daily surface temperature stands out as the covariate with the highest normalized impact on daily summer $\mathrm{O}_{3}$ levels, many other variables also play important roles, especially in the south and southeast regions (Fig. 4, bottom panels). Water vapor generally reduces $\mathrm{O}_{3}$ levels under pristine conditions, removing dissociated excited oxygen atoms and producing the hydroxyl radical $(\mathrm{OH})$. Under polluted conditions this negative effect competes with increased $\mathrm{O}_{3}$ production as a result of $\mathrm{OH}$ reacting with carbon monoxide (CO) or volatile organic compounds (VOCs), $\mathrm{O}_{3}$ precursors common to highly polluted environments. These two effects combine to produce generally weak correlations be- tween humidity and $\mathrm{O}_{3}$ in model perturbation studies (Jacob and Winner, 2009). In this work, however, relative humidity (RH) has a strong negative relationship with $\mathrm{O}_{3}$ in many locations, particularly in the south, consistent with previous analyses of observed sensitivities (e.g., Camalier et al., 2007). A negative correlation with temperature and a positive correlation with cloudy, unstable conditions may explain the stronger associations found in the observations relative to those of model perturbation studies. Stability, in the form of turbulent kinetic energy (TKE) is also a strong performer at many sites, though less so for the 95th percentile than for the 50th. Finally, while fire proximity stands out at relatively few stations as a dominant driver of median $\mathrm{O}_{3}$ levels 
Table 2. Selected covariates for $\mathrm{O}_{3}$ and $\mathrm{PM}_{2.5}$ using 90th percentile (above) and 50th percentile (below) quantile regressions. "Core" covariates (in bold) were selected using a minimum threshold for summed inverted ranks of at least 2, with remaining covariates added by rerunning the selection procedure including all core variables and a relaxed selection threshold of 1 .

\begin{tabular}{|c|c|c|c|}
\hline${\text { Summer } \mathrm{O}_{3}}$ & Winter $\mathrm{O}_{3}$ & Summer $\mathrm{PM}_{2.5}$ & Winter $\mathrm{PM}_{2.5}$ \\
\hline \multicolumn{4}{|c|}{ Elected via 90th percentile QR } \\
\hline $\begin{array}{l}\text { rhum.2m_mean } \\
\text { vwnddir.10m_mean } \\
\text { air.2m_max } \\
\text { crain_9x9_daymean } \\
\text { fire } \\
\text { uwnddir.10m_mean } \\
\text { air.sfc_9x9_min.6daymin } \\
\text { pres.sfc_daymax } \\
\text { tke.hl1_9x9_max } \\
\text { dswrf_daymin.3daymean } \\
\text { hpbl_max } \\
\text { tcdc_9x9_mean } \\
\text { dswrf_min.6daymin } \\
\text { vwnd.500_daymax.3daymean } \\
\text { shum.2m_max.diff } \\
\text { wspd.10m_daymin.3daymin } \\
\text { hpbl_daymin.6daymin } \\
\text { pres.sfc_min.diff } \\
\text { apcp_daymin.3daymax }\end{array}$ & $\begin{array}{l}\text { dswrf_mean.6daymax } \\
\text { wspd.10m_mean } \\
\text { vwnddir.10m_mean } \\
\text { rhum.2m_min } \\
\text { fire } \\
\text { rpi_max } \\
\text { hpbl_daymax } \\
\text { air.sfc_9x9_nightmin.6daymean } \\
\text { dlwrf_daymax.6daymin } \\
\text { crain_9x9_max } \\
\text { uwnddir.10m_daymean } \\
\text { tcdc_9x9_mean } \\
\text { lts_nightmax.3daymin } \\
\text { lftx4_min.diff } \\
\text { lcdc_9x9_nightmin.6daymax }\end{array}$ & $\begin{array}{l}\text { air.2m_max } \\
\text { vwnddir.10m_mean } \\
\text { lftx4_daymin } \\
\text { uwndddir.10m_mean.3daymean } \\
\text { wspd.10m_max.3daymean } \\
\text { air.sfc_9x9_nightmin.6daymean } \\
\text { fire } \\
\text { crain_9x9_max.6daymean } \\
\text { vwnddir.10m_daymean.6daymean } \\
\text { apcp_nightmax } \\
\text { rpi_nightmin } \\
\text { vvel.hl1_nightmax.6daymax } \\
\text { hpbl_nightmax.6daymax } \\
\text { rpi_nightmax.6daymin } \\
\text { tcdc_9x9_max.6daymax } \\
\text { shum.2m_min.diff } \\
\text { lts_nightmin.6daymin } \\
\text { mcdc_9x9_nightmax.3daymin }\end{array}$ & $\begin{array}{l}\text { hpbl_mean } \\
\text { vwnddir.10m_mean } \\
\text { tke.hl1_9x9_daymax.3daymean } \\
\text { wspd.10m_nightmax } \\
\text { rhum.2m_mean } \\
\text { shum.2m_ddaymax.6daymin } \\
\text { crain_9x9_nightmean } \\
\text { lts_min.3daymin } \\
\text { uwnddir.10m_mean.3daymean } \\
\text { dswrf_max.3daymean } \\
\text { lftx4_nightmin.6daymin } \\
\text { wspd.500_min } \\
\text { tke.hl1_9x9_max.6daymin } \\
\text { vwnd.500_max.diff } \\
\text { tcdc_9x9_max.diff } \\
\text { wspd.10m_min.6daymax }\end{array}$ \\
\hline \multicolumn{4}{|c|}{ Selected via 50th percentile QR } \\
\hline $\begin{array}{l}\text { rhum.2m_mean } \\
\text { air.2m_max } \\
\text { dswrf_daymin.3daymean } \\
\text { vwnddir.10m_mean } \\
\text { crain_9x9_daymean } \\
\text { fire } \\
\text { tke.hl1_9x9_daymax } \\
\text { uwnddir.10m_daymean.3daymean } \\
\text { air.sfc_9x9_daymin.3daymean } \\
\text { rpi_max } \\
\text { lts_mean } \\
\text { dswrf_min.6daymin } \\
\text { vwnd.500_min } \\
\text { hpbl_nightmean.3daymin } \\
\text { vvel.hl1_mean.6daymean } \\
\text { pres.sfc_mean.diff } \\
\text { rhum.2m_max.diff } \\
\text { vwnd.500_min.diff }\end{array}$ & $\begin{array}{l}\text { dswrf_mean } \\
\text { wspd.10m_mean } \\
\text { dswrf_daymean.diff } \\
\text { vwnddir.10m_mean } \\
\text { lts_daymin } \\
\text { shum.2m_min } \\
\text { uwnddir.10m_mean } \\
\text { crain_9x9_daymax } \\
\text { dswrf_min.3daymin } \\
\text { fire } \\
\text { air.sfc_9x9_mean.6daymean } \\
\text { hpbl_daymax } \\
\text { hcdc_9x9_daymax } \\
\text { pres.sfc_nightmin.6daymean } \\
\text { rpi_nightmax.6daymean } \\
\text { air.sfc_9x9_nightmin.diff } \\
\text { lts_daymax.6daymin } \\
\text { mcdc_9x9_nightmax.3daymin }\end{array}$ & $\begin{array}{l}\text { air.2m_max } \\
\text { air.sfc_9x9_nightmin.6daymax } \\
\text { crain_9x9_nightmax } \\
\text { wspd.10m_max.3daymean } \\
\text { vwnddir.10m_mean } \\
\text { lftx4_mean } \\
\text { Its_daymin } \\
\text { uwnddir.10m_daymean.3daymean } \\
\text { shum.2m_daymean.diff } \\
\text { crain_9x9_max.6daymean } \\
\text { rpi_max } \\
\text { vwnd.500_min } \\
\text { vwnd.500_daymax.6daymax } \\
\text { pres.sfc_max } \\
\text { hgt.850_max.6daymax }\end{array}$ & $\begin{array}{l}\text { hpbl_mean } \\
\text { vwnddir.10m_mean } \\
\text { wspd.10m_daymax.3daymax } \\
\text { crain_9x9_nightmax } \\
\text { wspd.10m_nightmax } \\
\text { rhum.2m_mean } \\
\text { uwnddir.10m_mean } \\
\text { wspd.10m_max.3daymin } \\
\text { rpi_max } \\
\text { uwnddir.10m_nightmean.3daymean } \\
\text { dswrf_daymin.6daymax } \\
\text { lftx4_nightmin.3daymean } \\
\text { shum.2m_nightmin.6daymean } \\
\text { fire }\end{array}$ \\
\hline
\end{tabular}

(50th percentile), it appears to be important at far more sites when examining higher $\mathrm{O}_{3}$ levels (95th percentile).

While the top covariate frequencies shown in Fig. 4 can help identify dominant meteorological factors overall, they do not indicate spatial distributions or sensitivity magnitudes. The bottom panel of Fig. 4 and top panel of Fig. 6 address these aspects of selected top covariates, showing where each tends to drive pollutant variability, as well as how the sensitivity magnitudes are distributed overall. Spatially, the temperature sensitivity of 95 th percentile $\mathrm{O}_{3}$ levels appears to be most directly associated with coastal areas, though the strong negative relationship between relative humidity and $\mathrm{O}_{3}$ in the south likely includes temperature effects (Fig. 4, bottom panels). In general, the sensitivities of $\mathrm{O}_{3}$ to changes in temperature are greater for higher $\mathrm{O}_{3}$ quantiles, as shown by the in- creasing and flattening distributions for 95th quantile regression sensitivities compared to 50th and 5th quantile values (Fig. 6, upper left panel). In fact, quantile regression coefficients for the 95th percentiles averaged $0.9 \mathrm{ppb}^{\circ} \mathrm{C}^{-1}, 50 \%$ greater than mean 50th percentile sensitivities. This difference again highlights the importance of temperature in determining extreme $\mathrm{O}_{3}$ events, since increased temperatures could be expected to positively affect the magnitudes of high $\mathrm{O}_{3}$ days even more than would be expected based on average days. By comparison, downward shortwave radiation flux also shows up as a positive driver of high $\mathrm{O}_{3}$ levels, but displays much more consistent sensitivities across $\mathrm{O}_{3}$ quantiles (Fig. 6, upper right panel). 

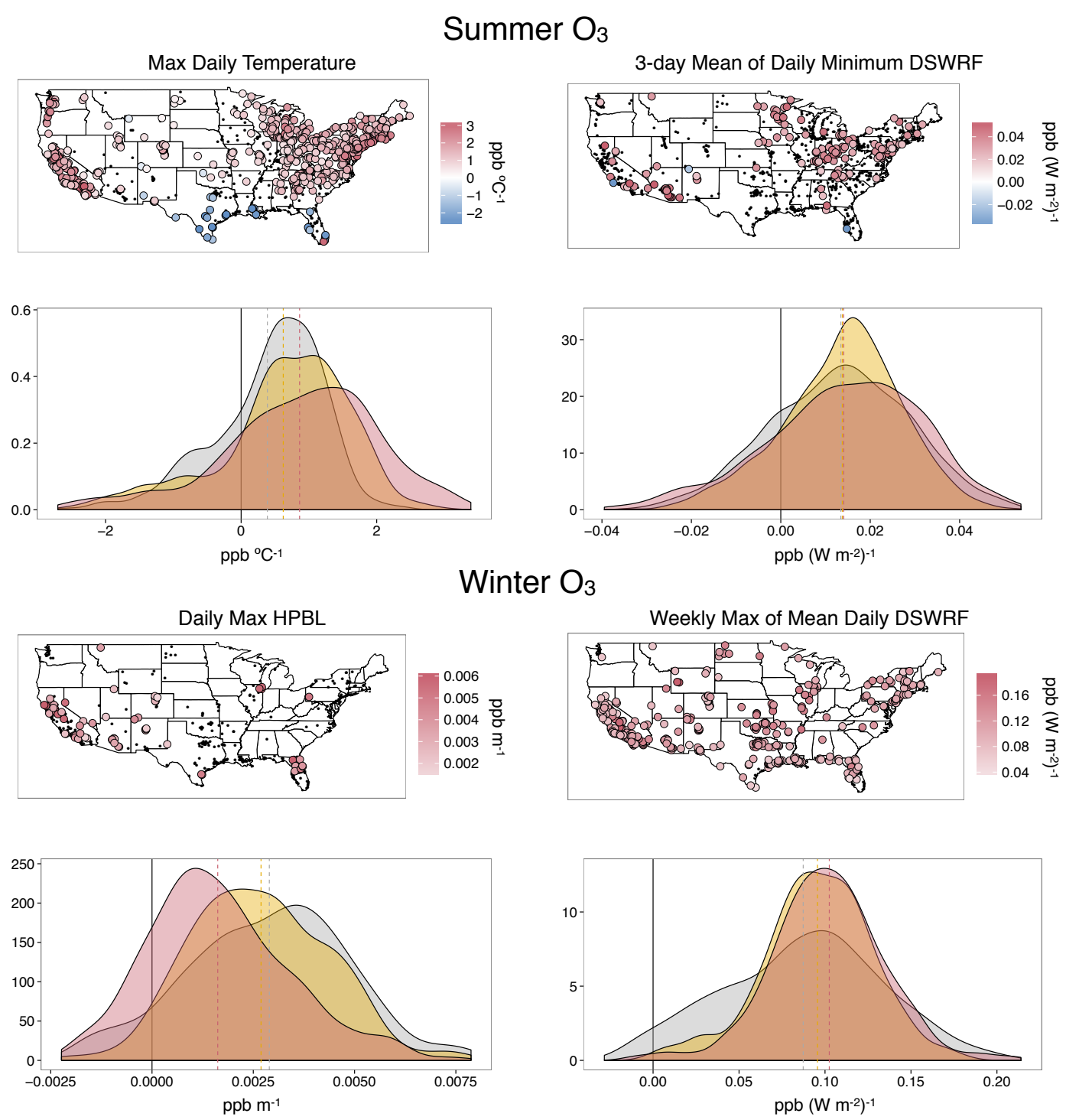

5th percentile

50 th percentile

95th percentile

Figure 6. Spatial and frequency distributions for key covariates of summer (top panels) and winter (bottom panels) $\mathrm{O}_{3}$. Maps show 95th percentile $\mathrm{O}_{3}$ sensitivities to selected meteorological variables at stations where that variable was most important (defined as being one of the top two normalized covariates). Below each map, histograms show the distribution of sensitivities for the 5th (gray), 50th (yellow), and 95th (red) percentiles at all sites.

\subsection{Winter $\mathrm{O}_{3}$}

$\mathrm{O}_{3}$ levels are generally lower at all percentiles during the winter months compared to the summer months, with 95th percentile $\mathrm{O}_{3}$ levels almost halved at some sites. As seen in Fig. 5, temperature is almost completely absent from the top ranks of $\mathrm{O}_{3}$ indicators during the winter. Instead, variables related to incoming radiation flux are most important at many sites, especially for 95 th percentile $\mathrm{O}_{3}$ levels. This indicates the relative importance of consistently clear skies for $\mathrm{O}_{3}$ production during the coldest months, a relationship that appears consistently across quantiles and re- gions (Fig. 5, bottom panels). Among the incoming radiation metrics, the 6-day maximum of daily mean shortwave radiation flux showed up as the top covariate most often, with consistently positive correlations evenly distributed spatially (Fig. 6, lower right panel). Sensitivities are slightly greater, on average, for higher quantiles, and stand out as particularly strong at stations in Wyoming, an area previously highlighted for its dangerously high winter $\mathrm{O}_{3}$ levels (e.g., Schnell et al., 2009). As with summer $\mathrm{O}_{3}$, downward shortwave radiation flux (DSWRF) again has a generally positive influence on winter $\mathrm{O}_{3}$, with some increase in sensitivity at higher quantiles. Planetary boundary layer height (HPBL) (Fig. 6, lower 


\section{Top Covariates: Summer PM2.5}

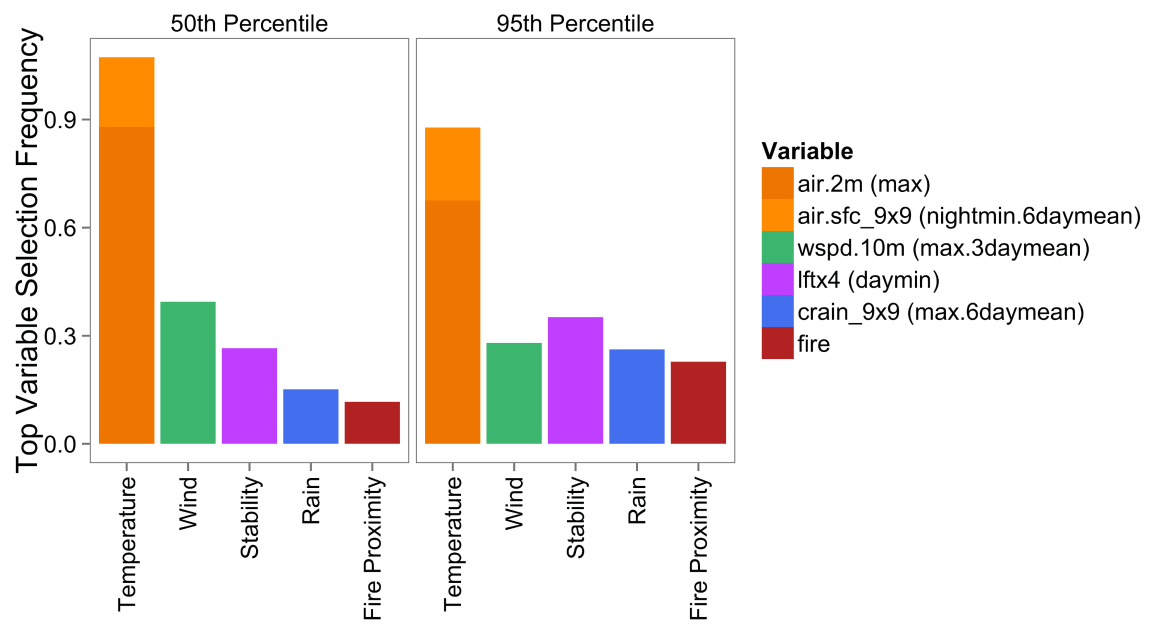

Normalized 95th Quantile Regression Coefficients for Most Frequent by Region

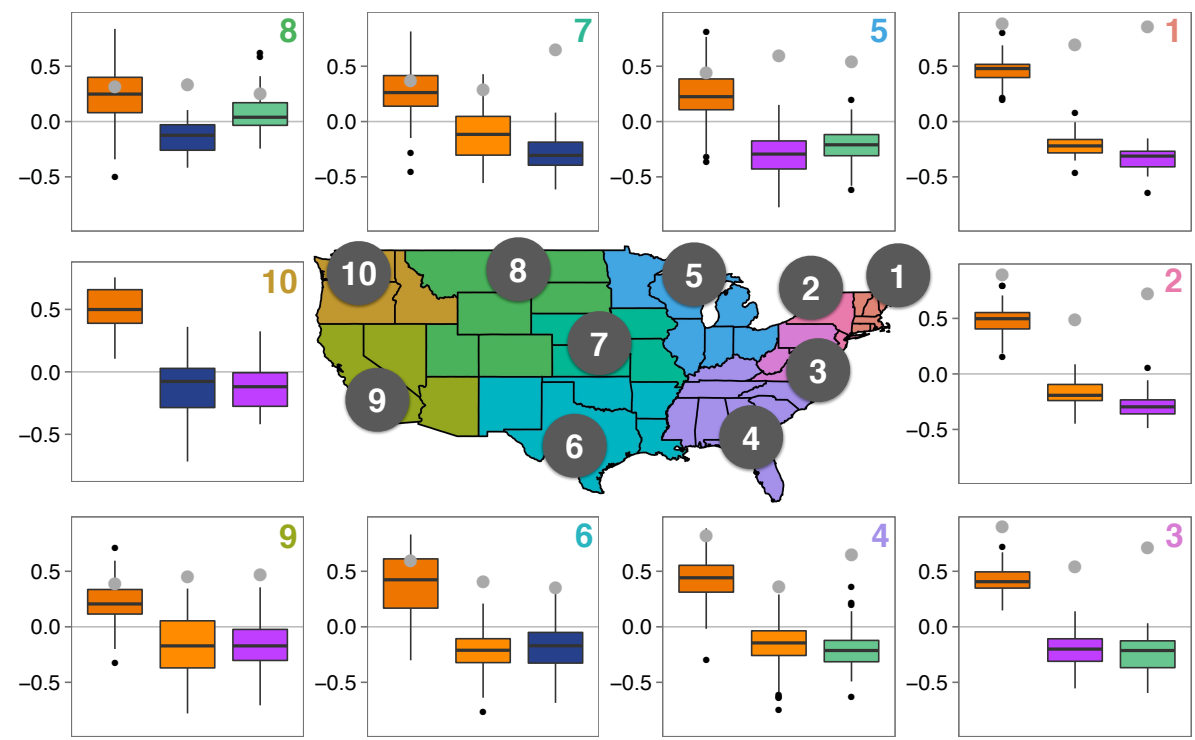

Figure 7. Same as Fig. 4 but for summer $\mathrm{PM}_{2.5}$.

left panel), wind, and specific humidity show up as top covariates at many sites as well, but more so for median quantile regressions than for 95 th percentiles, while fire proximity becomes increasingly important at the higher quantiles.

\subsection{Summer $\mathbf{P M}_{2.5}$}

Figure 7 shows that mean daily temperature is also a key player in predicting summertime $\mathrm{PM}_{2.5}$, with greater sensitivities at the highest concentration percentiles. While the previously discussed sensitivities of $\mathrm{O}_{3}$ to temperature shown in Fig. 6 are the greatest along both the northeast coast and Southern California, $\mathrm{PM}_{2.5}$ sensitivities to temperature peak entirely in the east (Fig. 9, upper left panel). One possible reason for this spatial difference in $\mathrm{PM}_{2.5}$ temperature sensitivity is the regionality of $\mathrm{PM}_{2.5}$ speciation, especially in terms of competing sensitivities of nitrate and sulfate aerosol (Dawson et al., 2007). While concentrations of nitrate aerosol (and, to a lesser extent, organics) are generally reduced by higher temperatures due to increased gas phase partitioning, sulfate aerosol concentrations can increase at higher temperatures because of increased rates of oxidation. Sulfur emissions are far higher in the east than in the west, offering a likely explanation for the differing sensitivities of $\mathrm{PM}_{2.5}$ to temperature between the regions.

In addition to temperature, 95th percentile $\mathrm{PM}_{2.5}$ shows strong sensitivities to wind speeds and tropospheric stability at many sites, emphasizing the importance of transport and stagnancy for extreme $\mathrm{PM}_{2.5}$ events, particularly those 


\section{Top Covariates: Winter PM2.5}

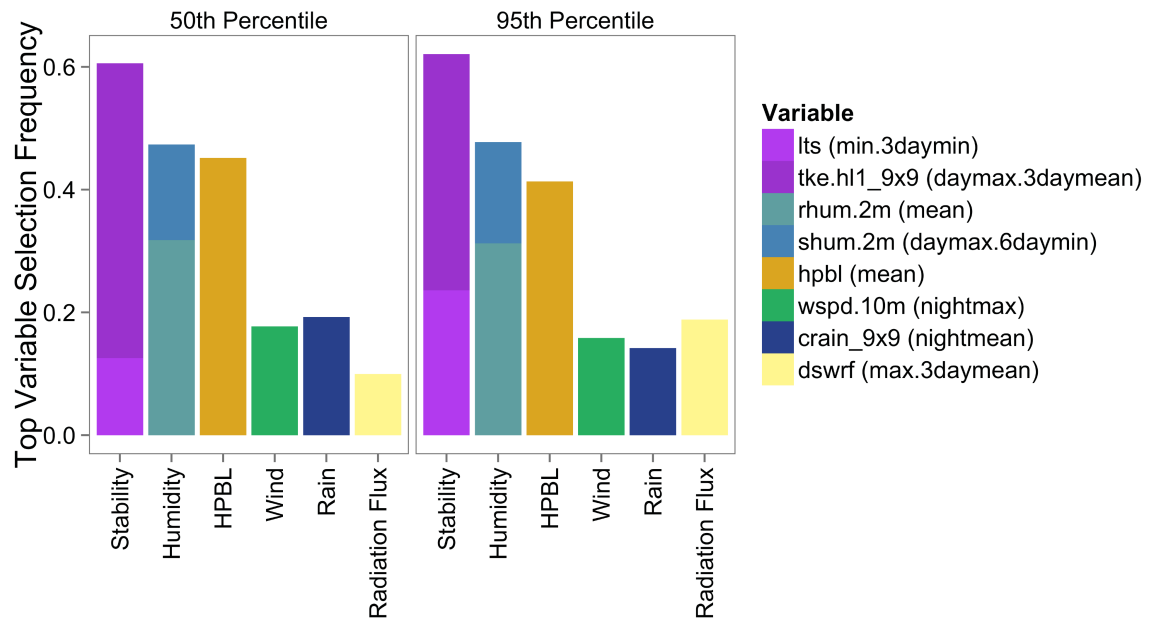

Normalized 95th Quantile Regression Coefficients for Most Frequent by Region

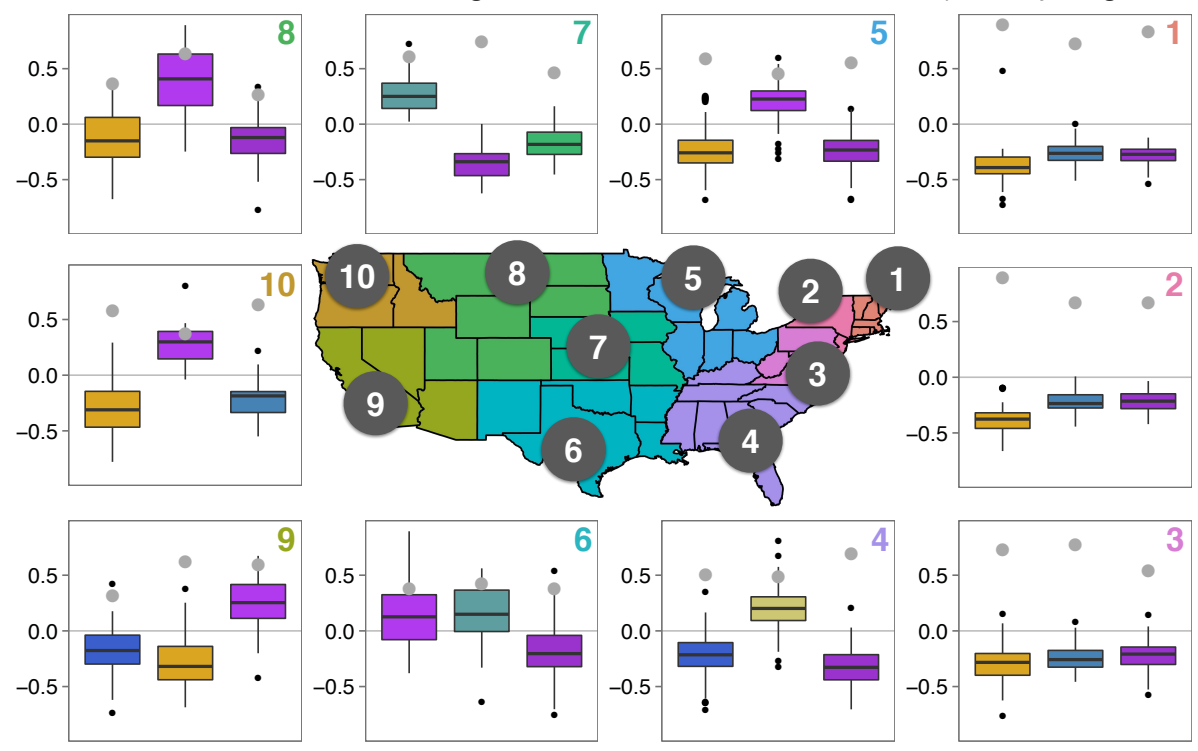

Figure 8. Same as for Fig. 4 but for winter $\mathrm{PM}_{2.5}$.

in highly polluted regions (Fig. 7, bottom panels). A total of 3-day average wind speed stood out among covariates at many sites throughout the east and midwest regions, and influences tended to be of higher magnitude for high-quantile $\mathrm{PM}_{2.5}$ levels than for medians or low quantiles (Fig. 9, upper right panel). Positive correlations for this metric may be associated with areas whose extremes were governed primarily by transport, rather than production. Also increasingly important for higher quantiles of fine particulate matter was fire proximity, with over twice as many sites including this metric in the top drivers for 95th percentile $\mathrm{PM}_{2.5}$ as for 50th percentile $\mathrm{PM}_{2.5}$.

\subsection{Winter $\mathbf{P M}_{2.5}$}

Unlike $\mathrm{O}_{3}$, winter $\mathrm{PM}_{2.5}$ levels in the USA are often comparable to (or even greater than) those of the summer months at many sites (Fig. 2). Compared to other seasons and species, the dominant covariates of winter $\mathrm{PM}_{2.5}$ are more consistently distributed between a few key variables (Fig. 8, top panel). Temperature is apparently less of a factor during cold months, rarely appearing among the top normalized indicators, and metrics related to stagnation stand out as important covariates associated with pollution events. Among meteorological covariates associated with increased winter $\mathrm{PM}_{2.5}$, stability metrics (TKE and LTS), relative humidity, and HPBL, stood out as key variables at the most sites, with 


\section{Summer $\mathrm{PM}_{2.5}$}
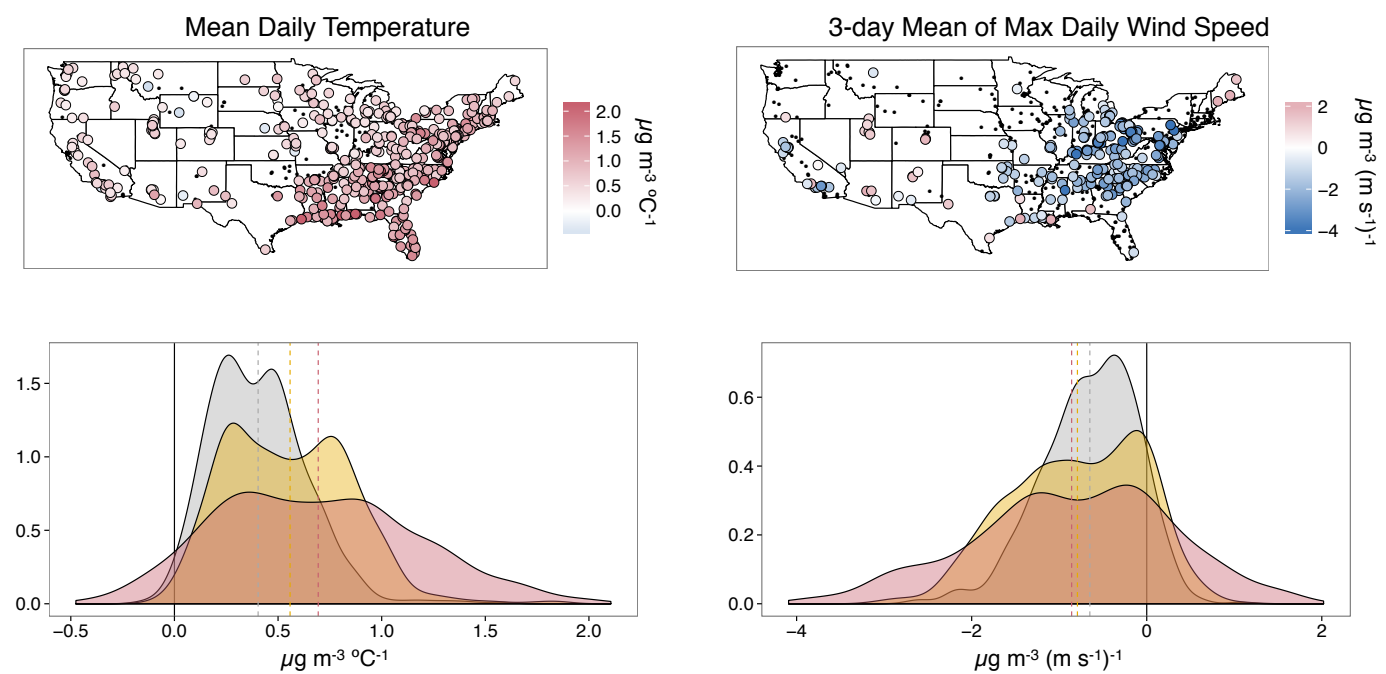

Winter $\mathrm{PM}_{2.5}$
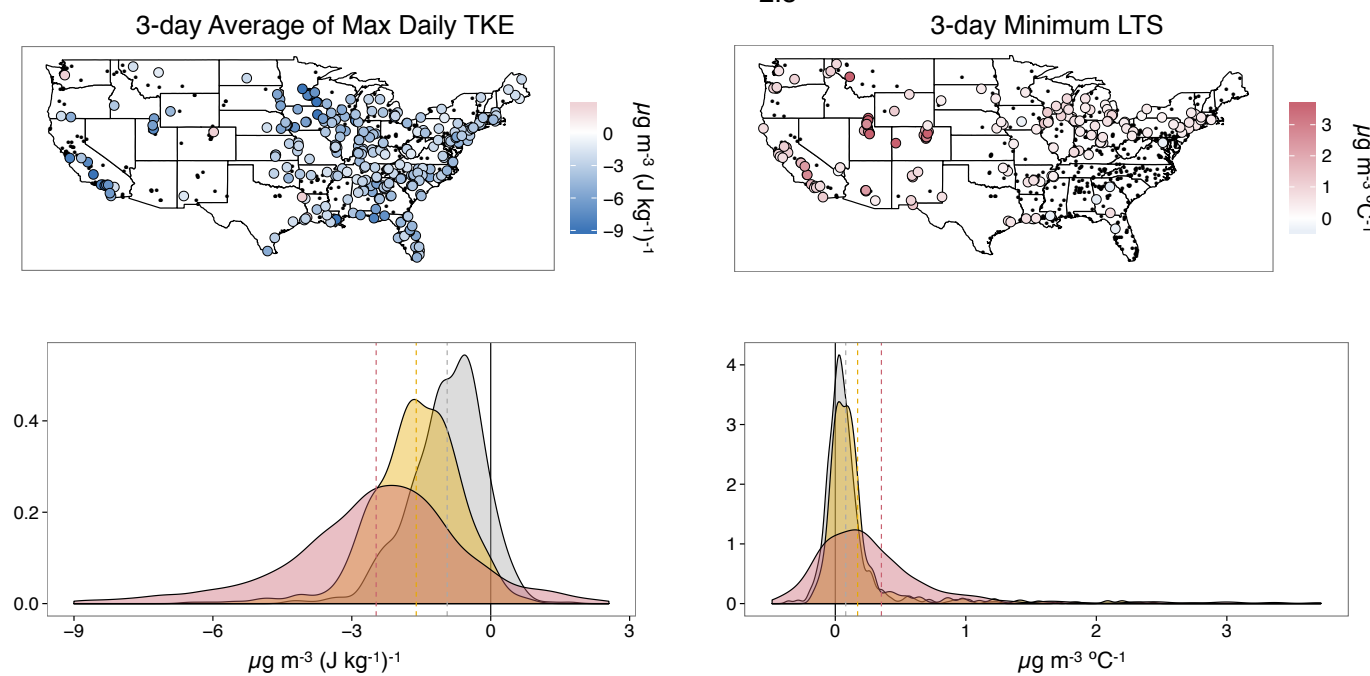

5th percentile

50th percentile

95th percentile

Figure 9. Same as Fig. 6 but for $\mathrm{PM}_{2.5}$.

wind and rainfall also important at many locations. Top covariates were particularly consistent in selection and magnitude in the northeast (regions 1,2, and 3), as shown by the tight, nearly identical distributions (Fig. 8, bottom panels). Turbulence had a consistently negative influence on winter $\mathrm{PM}_{2.5}$, especially for high response quantiles (Fig. 9, lower left panel).

Compared to factors connected to median $\mathrm{PM}_{2.5}$ levels, the two included tropospheric stability indicators (3-day average of max. daily TKE and 3-day minimum LTS) showed exceptionally strong sensitivities among covariates of 95th percentile levels, suggesting that $\mathrm{PM}_{2.5}$ extremes in the wintertime are particularly sensitive to persistently stable conditions (Fig. 9, lower right panel). Sites in Colorado and Utah, some of which are well-known for episodes of severely reduced winter air quality, stand out in this regard, with 95th quantile sensitivities to LTS over 4 times those of other site averages.

\section{Discussion}

\subsection{Differences in quantile sensitivities}

The differences between typical 5th, 50th, and 95th percentile sensitivities shown in Figs. 4, 5, 7 and 8, help to illustrate the ways in which meteorological impacts on pollutants can vary in magnitude across the response distribution. These differences can be more clearly quantified and compared by measuring the slope of a $\mathrm{QR}$ regression itself as a function of the percentile (Fig. 10). Using the full range of 


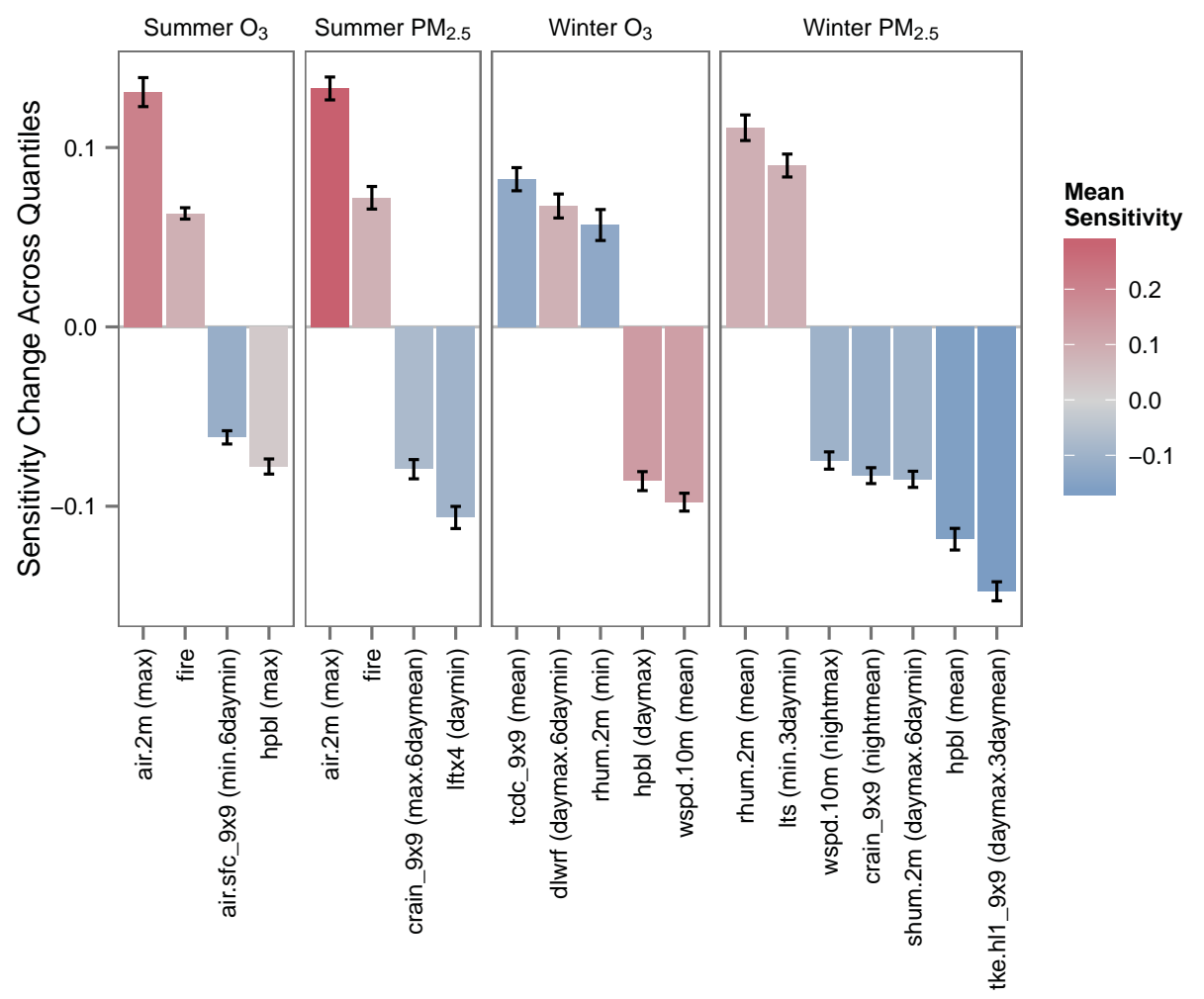

Figure 10. Normalized pollutant concentration sensitivities to meteorological covariates $(0.0=$ uniform sensitivity across quantiles $)$. Values shown here are the weighted least-squares regressions performed on normalized QR coefficients as a function of quantile for covariates with a mean sensitivity change of at least 0.05 , by species and season. Colors of bars show mean normalized sensitivities (roughly equivalent to slopes expected from an ordinary least-squares regression), while magnitudes of bars show mean change across quantiles, averaged over all stations. Error bars indicate standard error of the mean.

normalized QR output gathered, from 2 to $98 \%$, we perform weighted least-squares regressions for each selected variable at each station. The resulting slope for each regression (in normalized units of standard deviations) can be interpreted as a measure of change in sensitivity across the pollutant distribution, with high values representing strong positive differences in sensitivity, and low values representing strong negative differences. In other words, a zero slope implies that the response of a pollutant to a given meteorological covariate is relatively uniform regardless of the pollutant's concentration, while a positive slope implies that responses at the high extremes tend to be greater than those of lower percentiles. To put these changes in context, the overall mean sensitivity for each variable is shown in color. Quantifying the extent to which these differences in quantile sensitivities might impact the response distributions themselves is beyond the scope of this work, but the magnitudes of sensitivity differences relative to the mean sensitivities themselves suggest large differences between mean and extreme behavior. For example, the sensitivity change of summer $\mathrm{O}_{3}$ to maximum air temperature is shown to be roughly equivalent to the mean sensitivity itself. Thus, a location showing a mean increase of $1 \mathrm{ppb} \mathrm{O}_{3}{ }^{\circ} \mathrm{C}^{-1}$ might exhibit an increase of only
$0.5 \mathrm{ppb} \mathrm{O}_{3}{ }^{\circ} \mathrm{C}^{-1}$ at the 5 th percentile, but a much larger increase of $1.5 \mathrm{ppb} \mathrm{O}_{3}{ }^{\circ} \mathrm{C}^{-1}$ at the 95 th percentile. This could clearly have important consequences for the resulting $\mathrm{O}_{3}$ distribution, given increasing temperatures.

For summertime $\mathrm{O}_{3}$ and $\mathrm{PM}_{2.5}$, temperature stands out as a covariate that not only has a strong positive impact on concentrations (indicated by the bright red color), but also exhibits even stronger impacts on high-percentile pollutant levels than on lower percentile levels at most stations. On the other hand, while HPBL also strongly impacts summertime $\mathrm{O}_{3}$, the change in sensitivity between low and high quantiles is generally small, indicating a variable whose impact on $\mathrm{O}_{3}$ is relatively unchanging across pollutant percentiles. Besides temperature's connections to summer $\mathrm{O}_{3}$ and $\mathrm{PM}_{2.5}$, the key meteorological factors associated with winter $\mathrm{PM}_{2.5}$ stand out for having highly quantile-specific sensitivities. The sensitivity of $\mathrm{PM}_{2.5}$ to relative humidity, LTS, HPBL, and TKE are all greater for high $\mathrm{PM}_{2.5}$ quantiles than they are for low ones, highlighting the importance of characterizing the full pollutant response to meteorological covariates, especially for winter $\mathrm{PM}_{2.5}$. 


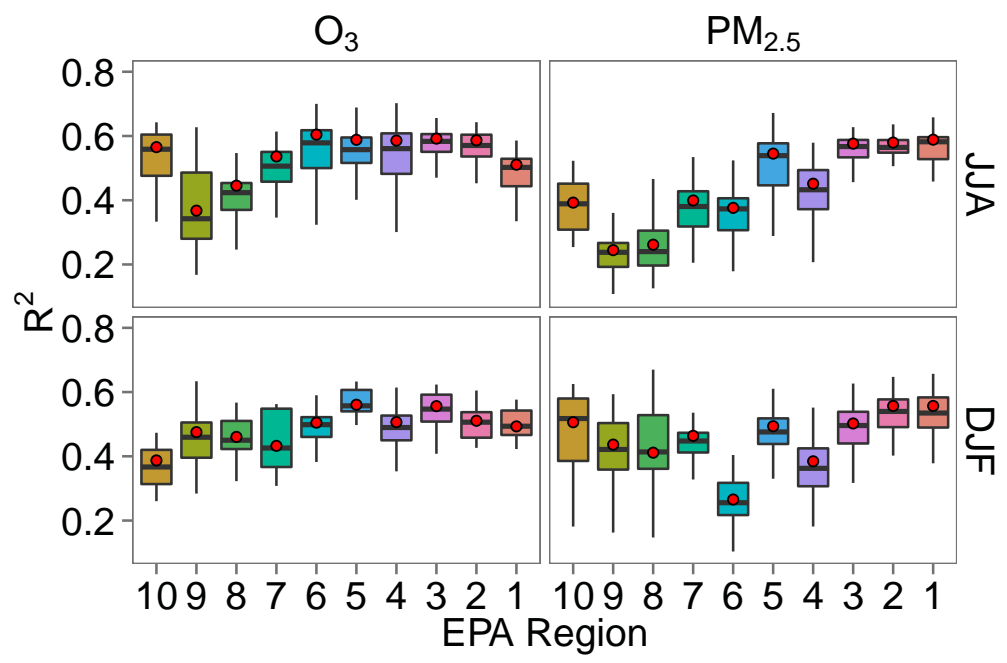

Figure 11. Ordinary least-squares coefficient of determination $\left(R^{2}\right)$ between observed pollutant concentrations and the reduced set of meteorological variables selected in this analysis. Results are shown by pollutant $\left(\mathrm{O}_{3}\right.$ or $\left.\mathrm{PM}_{2.5}\right)$, EPA region (see Figs. 4, 5, 7, and 8), and season (JJA is summer, DJF is winter). Red circles indicate median values using the full set of variables, for comparison. Refer to Table 2 for the listing of the reduced and full set of variables. Box plot whiskers mark 5th and 95th percentile $R^{2}$ values.

\subsection{Overall predictive power of statistical models}

The variables identified here were not selected based on their suitability for ordinary least-squares regression, but they do show considerable skill at predicting pollutant levels using this methodology, explaining over half of the variability at most sites (Fig. 11). Predictive skill for summertime $\mathrm{O}_{3}$ is greatest in east, south, and midwest (regions 2 through 6) and least in the Pacific southwest and mountain and plain regions (regions 8 and 9). Winter $\mathrm{O}_{3} R^{2}$ values are generally slightly lower than those of the summer months, especially in the Pacific northwest and US south central regions, though this may be partly explained by reduced $\mathrm{O}_{3}$ variability overall in the winter months.

$\mathrm{PM}_{2.5}$ shows a strong split between the relatively wellmodeled northeast and the less-accurately represented midwest and southwest. These results compare favorably to previous attempts to predict $\mathrm{PM}_{2.5}$ using meteorological indicators (Demuzere et al., 2009; Tai et al., 2010). Tai et al. (2010), for example, find multivariate linear regression capable of explaining less than $50 \%$ of $\mathrm{PM}_{2.5}$ variability in the northeastern USA. Almost half of the stations in those same regions showed adjusted $R^{2}$ values of greater than $60 \%$ using our method, despite the indicators being chosen to optimize high quantile regressions rather than OLS regressions. Regional differences in meteorological predictive power in this work are also comparable to those of Tai et al. (2010), who found high $R^{2}$ values in the northeast and Pacific northwest (regions 2, 3, and 5), and lower values in the south and mountain and plain regions (regions 6 and 8).

\subsection{Pollutant variability and trend}

It is apparent that relatively simple meteorological processes, chosen for their influence on high percentiles of $\mathrm{O}_{3}$ and $\mathrm{PM}_{2.5}$, are also capable of explaining a large fraction of daily pollutant variability. There are a number of possible sources for the remaining variability, including day-to-day fluctuations in pollutant precursor emissions and highly localized meteorological patterns. While the nationwide variable selection process of this study proved capable of identifying indicators that are broadly effective at predicting daily pollutant levels in many locations, specific features relevant to individual stations (e.g., direction and distance of upwind emission sources) may not be adequately represented by the globally selected variables. Variability in local emission sources themselves, either due to sporadic local events or differences in weekend vs. weekday emissions, may also play an important role at some sites. This analysis is also subject to uncertainties in the NARR product and the pollutant observations, as well as discrepancies between local station conditions and the grid-averaged NARR output.

Another important consideration in the analysis of these results is the nonstationarity of both pollutant concentrations and sensitivities. As a result of the implementation of widespread emissions controls, concentrations of $\mathrm{O}_{3}$ and $\mathrm{PM}_{2.5}$ have decreased dramatically in many of the most polluted areas in the USA. Since 2004, mean summertime $\mathrm{O}_{3}$ levels at the sites used in this study have decreased by an average of $0.14 \mathrm{ppb}$ per year, while 95 th percentile $\mathrm{O}_{3}$ levels have decreased by 0.58 ppb per year. Stations that started with exceptionally high $\mathrm{O}_{3}$ levels (mean summertime levels greater than $80 \mathrm{ppb}$ ) have seen even more dramatic decreases, 
with means falling by $0.63 \mathrm{ppb}$ per year and 95 th percentile levels falling by 1.3 ppb year.

To a certain extent, these changes in pollution levels over time are accounted for in our analysis through the inclusion of time (measured in days since the start of the analyzed record) as an indicator variable. However, changes in meteorological sensitivities themselves as a function of decreasing emissions are not accounted for. To assess how these decreases in emissions and overall pollution levels might have affected meteorological sensitivities, the analyses above were repeated using 4-year subsets of the full data record: 2004-2007 and 2008-2012, showing a widespread reduction in sensitivities over time, presumably due to changes in precursor emissions. For example, 95th percentile sensitivities of summertime $\mathrm{O}_{3}$ to temperature were $13 \%$ lower in the years 2009-2012 relative to 2004-2007, consistent with previously reported declines in temperature sensitivity (Bloomer et al., 2009). In all, we see average absolute differences in 95th percentile sensitivities among each station's top two covariates of $22 \%$, with most changes representing reductions in sensitivity. Despite these differences, the qualitative features of our analysis (including sign of sensitivities and differences between pollutant quantiles) are consistent over time.

\section{Conclusions}

This analysis demonstrates that air quality over the past decade was highly sensitive to meteorology, and that this sensitivity varied across pollutant type $\left(\mathrm{O}_{3}\right.$ vs. $\left.\mathrm{PM}_{2.5}\right)$, season, and concentrations (50th vs. 95th percentiles). These differences offer insights into the key drivers behind extreme pollution event frequencies in the observed record beyond simple conditional means, highlighting the meteorological covariates most associated with changes in the highest pollutant levels.

We find that temperature is a dominant covariate at most stations in the summer for both $\mathrm{O}_{3}$ and $\mathrm{PM}_{2.5}$, with relative humidity, stability, and radiation flux also key covariates relating to $\mathrm{O}_{3}$, and wind, stability, and rain often effective for predicting high $\mathrm{PM}_{2.5}$ levels. $\mathrm{O}_{3}$ variability during winter months is determined largely by changes in incoming radiation, while winter $\mathrm{PM}_{2.5}$ extremes are most commonly affected by stagnation, humidity, and HPBL. We show substantial regional variation in these results, suggesting that while classes of meteorological drivers of extreme air quality are generally consistent, specific factors leading to air-quality exceedances are local.

Climate change in coming decades is likely to induce a response in regional air pollution. The sensitivities of $\mathrm{O}_{3}$ and $\mathrm{PM}_{2.5}$ to changes in meteorological patterns are, in general, stronger for higher pollution percentiles, meaning that changes to certain factors (most notably temperature, wind speed, HPBL, and tropospheric stability) are likely to affect the magnitude and frequencies of pollutant extremes more drastically than they affect more moderate pollution levels. This effect suggests that regional changes to climate could have more significant impacts on the frequencies of extreme $\mathrm{O}_{3}$ and $\mathrm{PM}_{2.5}$ events than would be suggested by bulk sensitivities from OLS regressions.

This analysis framework offers new ways to investigate both the observed and simulated air-quality responses to climate. Through quantile regression, the selection and ranking of key predictors of pollutant variability can be evaluated robustly, focusing not on the mean behavior of a heavy-tailed pollutant distribution, but rather the sensitivities closer to the tail itself. Furthermore, the comparison of observed sensitivities to those simulated by regional or global air-quality models could identify key model biases relevant to the projection of future air quality, potentially providing insights on the underlying mechanistic reasons for those biases.

Acknowledgements. This work was supported by the EPA-STAR program. Although the research described in this article has been funded by the US EPA through grant/cooperative agreement (RD-83522801), it has not been subjected to the agency's required peer and policy review and therefore does not necessarily reflect the views of the agency, and no official endorsement should be inferred. The authors acknowledge Brian J. Reich for useful discussions.

Edited by: S. Brown

\section{References}

Alper-Siman Tov, D., Peleg, M., Matveev, V., Mahrer, Y., Seter, I., and Luria, M.: Recirculation of polluted air masses over the East Mediterranean coast, Atmos. Environ., 31, 1441-1448, doi:10.1016/S1352-2310(96)00321-4, 1997.

Banta, R. M., Senff, C. J., White, A. B., Trainer, M., McNider, R. T., Valente, R. J., Mayor, S. D., Alvarez, R. J., Hardesty, R. M., Parrish, D., and Fehsenfeld, F. C.: Daytime buildup and nighttime transport of urban ozone in the boundary layer during a stagnation episode, J. Geophys. Res., 103, 22519-22544, doi:10.1029/98JD01020, 1998.

Bell, M. L., Dominici, F., and Samet, J. M.: A MetaAnalysis of Time-Series Studies of Ozone and Mortality With Comparison to the National Morbidity, Mortality, and Air Pollution Study, Epidemiology, 16, 436-445, doi:10.1097/01.ede.0000165817.40152.85, 2005.

Bloomer, B. J., Stehr, J. W., Piety, C. A., Salawitch, R. J., and Dickerson, R. R.: Observed relationships of ozone air pollution with temperature and emissions, Geophys. Res. Lett., 36, L09803, doi:10.1029/2009GL037308, 2009.

Brasseur, G. P., Schultz, M., Granier, C., Saunois, M., Diehl, T., Botzet, M., Roeckner, E., and Walters, S.: Impact of climate change on the future chemical composition of the global troposphere, J. Climate, 19, 3932-3951, 2006.

Burnham, K. P. and Anderson, D. R.: Multimodel Inference Understanding AIC and BIC in Model Selection, Sociol. Meth. Res., 33, 261-304, doi:10.1177/0049124104268644, 2004. 
Camalier, L., Cox, W., and Dolwick, P.: The effects of meteorology on ozone in urban areas and their use in assessing ozone trends, Atmos. Environ., 41, 7127-7137, doi:10.1016/j.atmosenv.2007.04.061, 2007.

Dawson, J. P., Adams, P. J., and Pandis, S. N.: Sensitivity of $\mathrm{PM}_{2.5}$ to climate in the Eastern US: a modeling case study, Atmos. Chem. Phys., 7, 4295-4309, doi:10.5194/acp-7-4295-2007, 2007.

Demuzere, M., Trigo, R. M., Vila-Guerau de Arellano, J., and van Lipzig, N. P. M.: The impact of weather and atmospheric circulation on $\mathrm{O}_{3}$ and $\mathrm{PM}_{10}$ levels at a rural mid-latitude site, Atmos. Chem. Phys., 9, 2695-2714, doi:10.5194/acp-9-2695-2009, 2009.

Dockery, D. W., Pope, C. A., Xu, X., Spengler, J. D., Ware, J. H., Fay, M. E., Ferris, B. G., and Speizer, F. E.: An Association between Air Pollution and Mortality in Six U.S. Cities, N. England J. Med., 329, 1753-1759, doi:10.1056/NEJM199312093292401, 1993.

Geraci, M. and Bottai, M.: Quantile regression for longitudinal data using the asymmetric Laplace distribution, Biostat, 8, 140-154, doi:10.1093/biostatistics/kxj039, 2007.

Giglio, L., Descloitres, J., Justice, C. O., and Kaufman, Y. J.: An Enhanced Contextual Fire Detection Algorithm for MODIS, Remote Sens. Environ., 87, 273-282, doi:10.1016/S00344257(03)00184-6, 2003.

Heald, C. L., Henze, D. K., Horowitz, L. W., Feddema, J., Lamarque, J.-F., Guenther, A., Hess, P. G., Vitt, F., Seinfeld, J. H., Goldstein, A. H., and Fung, I.: Predicted change in global secondary organic aerosol concentrations in response to future climate, emissions, and land use change, J. Geophys. Res., 113, 116, doi:10.1029/2007JD009092, 2008.

Hogrefe, C., Lynn, B., Civerolo, K., Ku, J.-Y., Rosenthal, J., Rosenzweig, C., Goldberg, R., Gaffin, S., Knowlton, K., and Kinney, P. L.: Simulating changes in regional air pollution over the eastern United States due to changes in global and regional climate and emissions, J. Geophys. Res., 109, D22301, doi:10.1029/2004JD004690, 2004.

Jacob, D. J. and Winner, D. A.: Effect of climate change on air quality, Atmos. Environ., 43, 51-63, doi:10.1016/j.atmosenv.2008.09.051, 2009.

Jerrett, M., Burnett, R. T., Pope, C. A., Ito, K., Thurston, G., Krewski, D., Shi, Y., Calle, E., and Thun, M.: Long-Term Ozone Exposure and Mortality, N. England J. Med., 360, 1085-1095, doi:10.1056/NEJMoa0803894, 2009.

Justice, C. O., Giglio, L., Korontzi, S., Owens, J., Morisette, J. T., Roy, D., Descloitres, J., Alleaume, S., Petitcolin, F., and Kaufman, Y.: The MODIS fire products, Remote Sens. Environ., 83, 244-262, doi:10.1016/S0034-4257(02)00076-7, 2002.

Klein, S. A. and Hartmann, D. L.: The Seasonal Cycle of Low Stratiform Clouds, J. Climate, 6, 1587-1606, doi:10.1175/15200442(1993)006<1587:TSCOLS>2.0.CO;2, 1993.

Koenker, R. and Bassett Jr., G.: Regression Quantiles, Econometrica, 46, 33-50, 1978.

Krewski, D., Jerrett, M., Burnett, R. T., Ma, R., Hughes, E., Shi, Y., Turner, M. C., Pope, C. A., Thurston, G., Calle, E. E., Thun, M. J., Beckerman, B., DeLuca, P., Finkelstein, N., Ito, K., Moore, D. K., Newbold, K. B., Ramsay, T., Ross, Z., Shin, H., and Tempalski, B.: Extended follow-up and spatial analysis of the American
Cancer Society study linking particulate air pollution and mortality, Res. Rep. Health Eff. Inst., 140, 5-114, 2009.

Langford, A. O., Senff, C. J., Alvarez, R. J., Banta, R. M., and Hardesty, R. M.: Long-range transport of ozone from the Los Angeles Basin: A case study, Geophys. Res. Lett., 37, L06807, doi:10.1029/2010GL042507, 2010.

Lee, E. R., Noh, H., and Park, B. U.: Model Selection via Bayesian Information Criterion for Quantile Regression Models, J. Am. Stat. Assoc., 109, 216-229, doi:10.1080/01621459.2013.836975, 2014.

Levy, I., Mahrer, Y., and Dayan, U.: Coastal and synoptic recirculation affecting air pollutants dispersion: A numerical study, Atmos. Environ., 43, 1991-1999, doi:10.1016/j.atmosenv.2009.01.017, 2009.

Liao, H., Chen, W.-T., and Seinfeld, J. H.: Role of climate change in global predictions of future tropospheric ozone and aerosols, J. Geophys. Res., 111, D12304, doi:10.1029/2005JD006852, 2006.

Mesinger, F., DiMego, G., Kalnay, E., Mitchell, K., Shafran, P. C., Ebisuzaki, W., Jović, D., Woollen, J., Rogers, E., Berbery, E. H., Ek, M. B., Fan, Y., Grumbine, R., Higgins, W., Li, H., Lin, Y., Manikin, G., Parrish, D. and Shi, W.: North American Regional Reanalysis, B. Am. Meteorol. Soc., 87, 343-360, doi:10.1175/BAMS-87-3-343, 2006.

Mickley, L. J., Jacob, D. J., Field, B. D., and Rind, D.: Effects of future climate change on regional air pollution episodes in the United States, Geophys. Res. Lett., 31, L24103, doi:10.1029/2004GL021216, 2004.

Murazaki, K. and Hess, P.: How does climate change contribute to surface ozone change over the United States?, J. Geophys. Res., 111, D05301, doi:10.1029/2005JD005873, 2006.

Pope 3rd, C. A.: Respiratory hospital admissions associated with $\mathrm{PM}_{10}$ pollution in Utah, Salt Lake, and Cache Valleys, Arch. Environ. Health, 46, 90-97, 1991.

Pope III, C. A., Ezzati, M., and Dockery, D. W.: Fine-particulate air pollution and life expectancy in the United States, N. England J. Med., 360, 376-386, 2009.

Rasmussen, D. J., Fiore, A. M., Naik, V., Horowitz, L. W., McGinnis, S. J., and Schultz, M. G.: Surface ozone-temperature relationships in the eastern US: A monthly climatology for evaluating chemistry-climate models, Atmos. Environ., 47, 142-153, doi:10.1016/j.atmosenv.2011.11.021, 2012.

Schnell, R. C., Oltmans, S. J., Neely, R. R., Endres, M. S., Molenar, J. V., and White, A. B.: Rapid photochemical production of ozone at high concentrations in a rural site during winter, Nat. Geosci., 2, 120-122, doi:10.1038/ngeo415, 2009.

Schwarz, G.: Estimating the Dimension of a Model, Ann. Statist., 6, 461-464, doi:10.1214/aos/1176344136, 1978.

Steiner, A. L., Tonse, S., Cohen, R. C., Goldstein, A. H., and Harley, R. A.: Influence of future climate and emissions on regional air quality in California, J. Geophys. Res., 111, D18303, doi:10.1029/2005JD006935, 2006.

St. John, J. C. and Chameides, W. L.: Climatology of Ozone Exceedences in the Atlanta Metropolitan Area:? 1-Hour vs 8-Hour Standard and the Role of Plume Recirculation Air Pollution Episodes, Environ. Sci. Technol., 31, 2797-2804, doi:10.1021/es961068a, 1997.

Streets, D. G., Bond, T. C., Carmichael, G. R., Fernandes, S. D., Fu, Q., He, D., Klimont, Z., Nelson, S. M., Tsai, N. Y., Wang, M. Q., Woo, J.-H., and Yarber, K. F.: An inventory of gaseous and 
primary aerosol emissions in Asia in the year 2000, J. Geophys. Res., 108), 8809, doi:10.1029/2002JD003093, 2003.

Tai, A. P. K., Mickley, L. J., and Jacob, D. J.: Correlations between fine particulate matter $\left(\mathrm{PM}_{2.5}\right)$ and meteorological variables in the United States: Implications for the sensitivity of $\mathrm{PM}_{2.5}$ to climate change, Atmos. Environ., 44, 3976-3984, doi:10.1016/j.atmosenv.2010.06.060, 2010.

The World Health Organization (WHO): http://www.who.int/ mediacentre/news/releases/2014/air-pollution/en/ (last access: 13 May 2015), 2014.

Valente, R. J., Imhoff, R. E., Tanner, R. L., Meagher, J. F., Daum, P. H., Hardesty, R. M., Banta, R. M., Alvarez, R. J., McNider, R. T., and Gillani, N. V.: Ozone production during an urban air stagnation episode over Nashville, Tennessee, J. Geophys. Res., 103, 22555-22568, doi:10.1029/98JD01641, 1998.

Val Martin, M., Logan, J. A., Kahn, R. A., Leung, F.-Y., Nelson, D. L., and Diner, D. J.: Smoke injection heights from fires in North America: analysis of 5 years of satellite observations, Atmos. Chem. Phys., 10, 1491-1510, doi:10.5194/acp-10-14912010, 2010.
Wiedinmyer, C., Akagi, S. K., Yokelson, R. J., Emmons, L. K., AlSaadi, J. A., Orlando, J. J., and Soja, A. J.: The Fire INventory from NCAR (FINN): a high resolution global model to estimate the emissions from open burning, Geosci. Model Dev., 4, 625641, doi:10.5194/gmd-4-625-2011, 2011.

Wu, S., Mickley, L. J., Leibensperger, E. M., Jacob, D. J., Rind, D., and Streets, D. G.: Effects of 2000-2050 global change on ozone air quality in the United States, J. Geophys. Res., 113, D06302, doi:10.1029/2007JD008917, 2008.

Yang, Y.: Can the strengths of AIC and BIC be shared? A conflict between model indentification and regression estimation, Biometrika, 92, 937-950, doi:10.1093/biomet/92.4.937, 2005.

Yimin, M. and Lyons, T. J.: Recirculation of coastal urban air pollution under a synoptic scale thermal trough in Perth, Western Australia, Atmos. Environ., 37, 443-454, 2003.

Zhao, C., Wang, Y., and Zeng, T.: East China Plains: A "Basin" of Ozone Pollution, Environ. Sci. Technol., 43, 1911-1915, doi:10.1021/es8027764, 2009. 